\title{
Guar Gum: Structural and Electrochemical Characterization of Natural Polymer based Binder for Silicon-Carbon Composite Rechargeable Li-ion Battery Anodes
}

\author{
Ramalinga Kuruba ${ }^{1, *}$, Moni Kanchan Datta ${ }^{1,2, *}$, Krishnan Damodaran ${ }^{3}$, Prashanth H. Jampani ${ }^{1}$, \\ Bharat Gattu ${ }^{4}$, Prasad P. Patel ${ }^{4}$, Pavithra M. Shanthi ${ }^{1}$, Sameer Damle ${ }^{4}$ and Prashant N. \\ Kumta $^{1,2,4,5 @}$ \\ ${ }^{1}$ Bioengineering, Swanson School of Engineering, University of Pittsburgh, PA 15261 \\ ${ }^{2}$ Center for Complex Engineered Multifunctional Materials, Swanson School of Engineering, \\ University of Pittsburgh, PA 15261 \\ ${ }^{3}$ Department of Chemistry, University of Pittsburgh, PA 15260 \\ ${ }^{4}$ Chemical and Petroleum Engineering, Swanson School of Engineering, University of \\ Pittsburgh, PA 15261 \\ ${ }^{5}$ Mechanical Engineering and Materials Science, Swanson School of Engineering, University of \\ Pittsburgh, PA 15261 \\ *equal contribution \\ ${ }^{\circledR}$ Corresponding author: Prashant N. Kumta (pkumta@pitt.edu) \\ Department of Bioengineering, 815C Benedum Hall, 3700 O'Hara Street, Pittsburgh, PA 15261. \\ Tel: +1-412-648-0223, Fax: +1-412-624-3699
}




\begin{abstract}
Long term cyclability of a composite Li-ion anode electrode comprised of 82 wt.\% Si/C lithium ion active material along with $8 \mathrm{wt} . \%$ polymeric binder and $10 \mathrm{wt} . \%$ Super P conductive carbon black has been studied utilizing polymeric binders exhibiting different elastic/tensile moduli and tensile yield strengths. Accordingly electrochemically active Si/C composite synthesized by high energy mechanical milling (HEMM), exhibiting reversible specific capacities of $\sim 780 \mathrm{mAh} / \mathrm{g}$ and $\sim 600 \mathrm{mAh} / \mathrm{g}$ at charge/discharge rates of $\sim 50 \mathrm{~mA} / \mathrm{g}$ and $\sim 200 \mathrm{~mA} / \mathrm{g}$, respectively were selected as the Li-ion active anode. Polyvinylidene fluoride (PVDF) and purified guar gum (PGG) with reported elastic modulus $\sim 1000 \mathrm{MPa}$ and $\sim 3200 \mathrm{MPa}$, respectively were selected as the binders. Results show that the composite electrode ( $\mathrm{Si} / \mathrm{C}+$ binder + conducting carbon) comprising the higher elastic modulus binder (PGG) exhibits better long term cyclability contrasted with PVDF. ${ }^{1} \mathrm{H}$ NMR analysis of the polymer before and after cycling shows structural degradation/deformation of the low elastic modulus PVDF, whereas the high elastic modulus PGG binder shows no permanent structural deformation or damage. The results presented thus suggest that PGG based polymers exhibiting high elastic modulus are a promising class of binders with the desired mechanical integrity needed for enduring the colossal volume expansion stresses of $\mathrm{Si} / \mathrm{C}$ based composite anodes.
\end{abstract}

Key words: Binder; Silicon; Li-ion; Anode; Composite

\title{
1. Introduction
}

Rechargeable Li-ion battery (LIB) technology is considered as the frontrunner amongst various electrochemical energy storage (EES) devices due to its high usable specific energy $(\sim 100-200 \mathrm{Wh} / \mathrm{kg})$ and high operating $(\sim 3 \mathrm{~V}-5 \mathrm{~V})$ voltage window [1,2]. Despite considerable advancements, systems meeting the higher energy demand applications are still elusive for complete deployment in plug-in electric vehicles (PEV) or electric vehicles (EV) systems due to the limited energy and power densities [1-4]. In order to further improve the energy density of LIBs to render them amenable for higher energy application $(\geq 300 \mathrm{Wh} / \mathrm{kg})$, alternative Si based anode materials with an attractive theoretical specific capacity $\sim 4200 \mathrm{~mA} / \mathrm{g}$ representing a $\sim 10$ fold increment over the traditionally used graphite anode has been extensively studied in recent 
years [1,3,5-11]. The ubiquitous structural disintegration of $\mathrm{Si}$ during repeated alloying/dealloying following colossal volume expansion $(\sim 300 \%)$, and the resultant capacity fade within few tenths of cycles is universally reported [12-15]. In order to improve the structural stability/integrity as well as the long term cyclability of Si based anodes, nanotechnology and nanoscale architectures have been explored for generating various nanoscale morphologies of $\mathrm{Si}$ (e.g. nanotube, nanowire, nano-droplet) and nano-composites of $\mathrm{Si}$ and $\mathrm{C}$ (e.g. $\mathrm{Si} / \mathrm{C}$ nanocomposite) [1,5-19]. Despite much advances, Si based nano-materials or nano-composite electrodes still display structural degradation and limited cyclability with a fade in capacity exceeding $0.1 \%$ per cycle.

Concomitant with the materials development work, there are several published reports demonstrating improvement in the cyclability of Si based active materials by proper design and effective development of composite electrode (active materials + binder + conducting carbon) exploiting the mechanical properties of the binder combined with effective interactions of the binder functional groups with the native silicon oxide layers on the Si surfaces [20-26]. Consequently, during the electrode manufacturing process, a small volume faction of inactive binder ( 2-8 wt.\%), facilitating uniform binding of the particles is homogeneously mixed with micron sized electro-active particles $(<40 \mu \mathrm{m})$ along with electronically conductive carbon (CC) (e.g. Super P carbon black) to yield a homogeneous slurry. The slurry is then cast onto suitable current collectors of few microns thick to form a particulate composite electrode. The particulate composite electrode generated on a suitable current collector must be structurally and chemically stable during repeated cycling of the electrode for at least a thousand or greater cycles. In the case of the widely used graphitic anode in commercial LIBs, the composite electrode utilize PVDF as a binder displaying excellent cyclability during the charge/discharge processes [27,28].

The mechanical stress/strain generated on graphite as well as the electrode during alloying and dealloying processes with $\mathrm{Li}$-ion ( $10 \%$ volume change) is expected to lie within the elastic limit of graphite and the composite electrode. Hence the systems do not exhibit any permanent deformation or mechanical degradation of graphite or the intercalated $\mathrm{LiC}_{6}$ phase $[27,28]$. However, it is well-known that PVDF commonly used in commercial graphitic anodes, is not suitable for $\mathrm{Si}$ based active materials [20-26,29,30]. The tremendous mechanical stress/strain beyond the elastic limit generated within the composite electrode $(\mathrm{Si}+$ binder $+\mathrm{CC})$ 
results inevitably in plastic deformation of $\mathrm{Si}$ based composite electrode causing the well-known mechanical degradation or permanent deformation of the composite electrode leading to loss of contact between the active material with the current collector causing capacity loss in within few tenths of cycles.

Improvement in cycling of $\mathrm{Si}$ based composite electrode clearly requires indigenous engineering of the mechanical properties of the composite electrode to achieve optimum elastic modulus, strength and toughness, and low stress/strain on the composite electrode (within the elastic limit) by proper distribution of the generated stress/strain within the composite electrode. It is well known that the mechanical properties (e.g. elastic modulus, fracture strength) of the particulate composite electrode and stress/strain distribution within the composite electrode depend on the mechanical properties, which in turn depend on the volume fraction of the binder matrix as well as the dispersed active particles following the Halpin-Tsai equation [31]. In this regard, stiffer (high elastic modulus) binders such as water soluble Na-Carboxymethyl cellulose (Na-CMC), polyacrylic acid (PAA), sodium alginate based binder and different blended polymers have been recently identified as better choices compared to PVDF for Si based system. However, despite the novelty and improved initial performance, they all exhibit degradation over several cycles [20-26,29,30] casting doubts on their long term performance. In the present investigation novel water soluble, biodegradable, non-toxic and good film forming ability of polysaccharide based binders namely, purified guar gum (PGG) obtained after purification of raw guar gum has been studied as a potential binder system for the $\mathrm{Si} / \mathrm{C}$ nanocomposite electrode system. The biodegradable nature of the system further adds to the possibility of green engineering and the environmentally benign aspect of polymeric binder systems for LIB.

Guar gum is a natural nonionic polysaccharide extracted from the refined endosperm of cluster bean seeds, chemically classified as galactomannan. It is basically composed of a straight chain backbone of D-mannose units, united by $\beta$ (1-4) glycoside linkages, and bears a single Dgalactose side chain unit on approximately every alternate mannose, joined to it by an $\alpha$ (1-6) glycoside linkage (see Fig. 1) [32,33] making it an attractive system for exploring as a binder for LIBs as indicated in the present study. In recent publication, gaur gum and its derivative has been reported as a suitable binder for silicon nanoparticles which shows excellent electrochemical performance $[34,35]$. In the present study, contrary with the published reports, Si/C composite 
consisting of more ubiquitous micron-sized $\mathrm{Si}$ dispersed on graphite matrix obtained by cost effective high energy ball milling has been used as a Li-ion active material to study the cyclability of the composite electrode $(\mathrm{Si}+$ binder $+\mathrm{CC}$ ) based on PGG binder and $\mathrm{Si} / \mathrm{C}$ active materials. In addition, fundamental study of the change in molecular structure of the binder during Li-ion cycling determined by proton nuclear magnetic resonance $\left({ }^{1} \mathrm{H}-\mathrm{NMR}\right)$ of PGG along with PVDF before and after electrochemical cycling has been reported in this article. The $\mathrm{Si} / \mathrm{C}$ Li-ion active materials, synthesized by high energy mechanical milling (HEMM) as reported by the present authors in earlier publications [16,36] exhibiting a reversible capacity $\sim 780 \mathrm{mAh} / \mathrm{g}$ at $\mathrm{C}$ rate of $\mathrm{C} / 16(\sim 50 \mathrm{~mA} / \mathrm{g})$ has also been selected as the electrochemically active anode system for this study.

\section{Experimental Section}

\subsection{Materials Synthesis}

Mixtures of elemental powders of synthetic graphite (Aldrich, 1-2 $\mu \mathrm{m}$ ), Si (Alfa aesar, 325 mesh) and poly-acrylonitrile (PAN) $\left(\mathrm{M}_{\mathrm{w}} \sim 150,000\right.$, Aldrich) of elemental composition 56 wt.\% Gr-14 wt.\% Si-30 wt.\% PAN were subjected to high energy mechanical milling (HEMM) in a high energy shaker mill (SPEX CertiPrep $8000 \mathrm{M}$ ) up to $10 \mathrm{~h}$ in a stainless steel (SS) vial using $20 \mathrm{SS}$ balls of $2 \mathrm{~mm}$ diameter $(\sim 20 \mathrm{~g})$ with a ball to powder weight ratio 10:1. Specifically, $0.6 \mathrm{~g}$ of PAN was dissolved in $\sim 8 \mathrm{ml} \mathrm{N}$-methylpyrrolidone (NMP) to form a homogeneous solution. Graphite $(\sim 1 \mathrm{~g}), \mathrm{Si}(\sim 0.4 \mathrm{~g})$, and the PAN solution were batched in a vial inside an argon filled glove box ( $\sim 10 \mathrm{ppm}$ oxygen and $\sim 0.10 \mathrm{ppm}$ moisture $)$ in order to prevent oxidation of the reactive Si components during milling. Decomposition of PAN to form PAN-based carbon (PAN-C) $[16,36]$ was obtained by isothermally annealing the mechanically milled powders at $\sim 973 \mathrm{~K}$ for $6 \mathrm{~h}$ in an ultrahigh purity argon (UHP-Ar) atmosphere using a heating rate of $10 \mathrm{~K} \mathrm{~min}{ }^{-1}$ and a flow rate of $100 \mathrm{~mL} \mathrm{~min}^{-1}$. The $\mathrm{Si} / \mathrm{C}, \mathrm{Li}$-ion active composite powder obtained after thermal treatment at $\sim 973 \mathrm{~K}$ is further intentionally ball milled for 2 min to destroy the composite inherent structure which is expected to shows inferior cyclability/stability in comparison to the heat treated $\mathrm{Si} / \mathrm{C}$ composite. 
Commercial dried PVDF powder $\left(\mathrm{M}_{\mathrm{w}} \sim 534,000\right.$, Aldrich) was dissolved in anhydrous NMP (N-methyl-2-pyrrolidone, Aldrich) to prepare a $5 \mathrm{wt} \%$ PVDF solution. On the other hand, raw gaur gum (Aldrich) was purified via Soxhlet extraction with ethanol following the method described by Cunha et al. [37]. Accordingly, Guar gum (20 g) was treated by Soxhlet extraction with ethanol for four days. The obtained product was then hydrated in distilled water $(1000 \mathrm{~mL})$ and mixed via magnetic stirring for $4 \mathrm{~h}$, followed by centrifugation at $2000 \mathrm{rpm}$ for 25 minutes. The supernatant was then precipitated in acetone, filtered and washed with ethanol three times followed by vacuum drying. The dried PGG powder has been dissolved in high purity deionized water to prepare a $5 \mathrm{wt} \%$ PGG solution. The above mentioned stock solution of PVDF and PGG has been used to prepare the composite electrode with $\mathrm{Si} / \mathrm{C}$ as Li-ion active material containing Super $\mathrm{P}$ as the conductive carbon. Table 1 shows the reported molecular weight and mechanical properties (film based) of PVDF and PGG binders used for this study [32,38-40]. The reported mechanical properties of PVDF and PGG have been measured using ASTM D882 method.

The composite electrodes were prepared by mixing $82 \mathrm{wt} . \%$ of the active Si/C powder of -325 mesh $(<44 \mu \mathrm{m})$ and 10 wt.\% Super P (SP) conductive carbon black (TIMCAL). The binder solution corresponding to $\sim 8 \mathrm{wt} . \%$ binder with respect to the electrode composition is added to the mixture to form a slurry. The as prepared homogenous slurry was then coated onto a $\mathrm{Cu}$ foil and dried at $110^{\circ} \mathrm{C}$ under vacuum for $24 \mathrm{~h}$. Circular disc of $\sim 1 \mathrm{~cm}^{2}$ area was cut from the dried foil to contain a $\mathrm{Si} / \mathrm{C}$ active materials loading in the range $\sim 3.0-3.5 \mathrm{mg} \mathrm{cm}^{-2}$ irrespective of binder used.

\subsection{Materials Characterization}

In order to perform qualitative phase analysis, the milled powders as well as heat treated powders were characterized by X-ray diffraction (XRD) using the Philips XPERT PRO system employing the $\mathrm{Cu} \mathrm{K} \mathrm{K}_{\alpha}(\lambda=0.15418 \mathrm{~nm})$ radiation. To investigate the microstructure of the as prepared $\mathrm{Si} / \mathrm{C}$ composites as well as the electrochemically cycled electrode, scanning electron microscopy (SEM) analysis was conducted. Quantitative elemental analysis and distribution of the elements (by X-ray mapping) in the Si/C composite was further investigated using the energy dispersive X-ray (EDS) analyzer attached with the SEM. Philips XL-30FEG equipped with an 
EDS detector system comprised of an ultrathin beryllium window and $\mathrm{Si}(\mathrm{Li})$ detector operating at $25 \mathrm{kV}$ was employed for the secondary electron (SE) image, elemental and X-ray mapping analyses. Fourier Transform Infrared (FTIR) spectroscopy measurements has been performed using a Thermo-Nicolet (Thermo Electron Corporation, USA) FTIR spectrometer. All samples have been analyzed in the attenuated total reflectance (ATR) mode using a Diamond ATR accessory. For each spectrum 32 scans were collected at a resolution of $4 \mathrm{~cm}^{-1}$ from $4000 \mathrm{~cm}^{-1}$ to $500 \mathrm{~cm}^{-1}$. ${ }^{1} \mathrm{H}-\mathrm{NMR}$ analysis has also been conducted on the PVDF and PGG binders before and after the electrochemical cycling tests to understand the change in molecular structure of the polymeric binder during electrochemical cycling. The PGG binder in the pure form has been dissolved in deuterium oxide $\left(\mathrm{D}_{2} \mathrm{O}\right)$, whereas PVDF in the pure form has been dissolved in dimethyl sulfoxide (DMSO- $\mathrm{d}_{6}$ ) with a concentration of $5 \mathrm{mg} / \mathrm{ml}$ for conducting the ${ }^{1} \mathrm{H}-\mathrm{NMR}$ study. The NMR spectra collected for PGG and PVDF in the pure form has been considered and referred to as before cycling spectra. On the other hand, the composite electrode obtained after $111^{\text {th }}$ cycle has been washed thoroughly with Dimethyl carbonate (DMC) solvent to remove any electrolyte and other soluble species. The PGG and PVDF binder was then isolated from the washed cycled electrode following dissolution in the respective solvents, e.g. $\mathrm{PGG}+\mathrm{Si} / \mathrm{C}+\mathrm{SP}$ in deuterium oxide $\left(\mathrm{D}_{2} \mathrm{O}\right)$ and $\mathrm{PVDF}+\mathrm{Si} / \mathrm{C}+\mathrm{SP}$ in dimethyl sulfoxide (DMSO- $\left.\mathrm{d}_{6}\right)$. The solution containing the soluble binder is then separated from $\mathrm{Si} / \mathrm{C}+\mathrm{SP}$ particles by filtration and subjected to ${ }^{1} \mathrm{H}-\mathrm{NMR}$ analysis. The ${ }^{1} \mathrm{H}-\mathrm{NMR}$ spectra of all the binders considered in this study in the pure form (considered as before cycling) and after electrochemical cycling have been recorded by Bruker Avance III $700 \mathrm{MHz}$ NMR spectrometer using a TXI probe. All of the ${ }^{1} \mathrm{H}-\mathrm{NMR}$ spectra have been collected with 16 to 32 scans at ambient temperatures.

Electrochemical characteristics of the composite electrodes were determined on electrodes that were prepared by mixing $82 \mathrm{wt} . \%$ of the active powder of -325 mesh, $10 \mathrm{wt} . \%$ Super P carbon (SP) and 8 wt.\% binder. A 2016 coin cell design was used by employing lithium foil as the counter electrode, the $\mathrm{Si} / \mathrm{C}$ composite as the working electrode and $1 \mathrm{M} \mathrm{LiPF}_{6}$ in ethylene carbonate/diethyl carbonate (EC/DEC $=1: 2$ in volume) as the electrolyte. All the cells tested in this study were cycled at room temperature $(\sim 298 \mathrm{~K})$ in the voltage range from $\sim 0.02$ to $\sim 1.2 \mathrm{~V}$ employing different discharge/charge rates $\left(\sim 50-200 \mathrm{mAg}^{-1}\right)$ and a minute rest period between the charge/discharge cycles using a potentiostat (Arbin electrochemical instrument). Electrochemical impedance spectroscopy (EIS) has been performed on the Versastat 3 (Princeton 
Applied Research Inc.) over a frequency range of $0.01 \mathrm{~Hz}-100 \mathrm{kHz}$. An A.C. amplitude of $5 \mathrm{mV}$ was used and the spectra were obtained before cycling and subsequent to the $1^{\text {st }}$ cycle discharge $\left(\mathrm{Li}^{+}\right.$alloying) and charge states $\left(\mathrm{Li}^{+}\right.$de-alloying), and in the charged state after the $20^{\text {th }}, 40^{\text {th }}$ and $80^{\text {th }}$ cycle, respectively. The electrode potential was stabilized after charge/discharge cycles and EIS was performed in order understand the charge storage behavior upon cycling. The effect of cycling on the electrode interfacial resistance and charge transfer parameters has been analyzed by performing equivalent circuit modeling using the Z-View software (Scribner Associates, Inc.; version 3.3).

\section{Results and discussion}

FTIR analysis was conducted on the PVDF and PGG binders to identify the different functional groups present in the studied polymer binder and also confirm their chemical structure. Accordingly, the spectra obtained from PGG and PVDF shown in Fig. 1 were analyzed. The FTIR spectrum of PGG shows the presence of a very strong and broad absorption band at $3287 \mathrm{~cm}^{-1}$ which can be assigned to stretching of the $\mathrm{O}-\mathrm{H}$ bond, while the sharp absorption band at $2916 \mathrm{~cm}^{-1}$ can be attributed to stretching vibrations corresponding to the $\mathrm{C}-\mathrm{H}$ bond in the $\mathrm{CH}$ groups. The bending of $\mathrm{C}-\mathrm{H}$ bond in $\mathrm{CH}_{2}$ group is assigned to an absorption band located at $1420 \mathrm{~cm}^{-1}$ and the bending of $\mathrm{C}-\mathrm{O}$ in $\mathrm{CH}_{2}-\mathrm{O}-\mathrm{CH}_{2}$ group appears in the $1016 \mathrm{~cm}^{-1}$ frequency region. On the other hand, the absorptions of the FTIR spectrum of PVDF indicate that the crystalline phase is present in both, $\alpha$ and $\beta$ conformations. The signals at 1401, 1178, $1066,877,840,532$ and $485 \mathrm{~cm}^{-1}$ were attributed to the $\beta$ conformation and the bands at 975 , 796 and $614 \mathrm{~cm}^{-1}$ were assigned to the $\alpha$ conformation. The other signals in the spectrum correspond to the vibrations arising from the amorphous phase of the polymer. These results are in good agreement with the FTIR signal characteristics already described in the literature for PGG and PVDF [32,33,41].

The XRD patterns of Si/C composite obtained from the 56wt.\% Gr-14 wt.\% Si-30 wt.\% PAN precursor after $10 \mathrm{~h}$ of mechanical milling followed by thermal treatment at $\sim 973 \mathrm{~K}$ in $\mathrm{Ar}$ atmosphere are shown in Fig. 2a. As shown in Fig. 2a, the XRD patterns of the 10h milled sample as well as the heat treated powder show the presence of graphite and silicon without any detectable amount of unwanted $\mathrm{SiC}$, similar to our earlier publications [16,36]. The composition of the $\mathrm{Si} / \mathrm{C}$ is estimated based on the $37 \%$ yield of PAN-C [16] and no weight loss of Si and 
graphite based on the thermal DSC/TGA analysis yielding approximately C-17.2 wt.\% Si. The secondary electron (SE) SEM image of heat treated sample obtained after heat treatment at $\sim 973 \mathrm{~K}$, shown in Fig. 2b, indicates the formation of irregularly shaped fine particles $(<0.5 \mu \mathrm{m})$. Elemental analysis using energy dispersive X-ray spectroscopy, shown in Fig. 2c, indicates the presence of $\mathrm{C}, \mathrm{Si}$ and iron $(\mathrm{Fe})$ in the $\mathrm{Si} / \mathrm{C}$ active materials. Appearance of the $\mathrm{Fe}$ peak in the EDS (Fig. 2c) analysis mainly arises from the iron contamination in the milled sample due to the SS milling media used causing frictional wear following impingement of the harder Si and graphite particles with the relatively soft SS balls and the SS walls of the container. In order to determine the distribution of the $\mathrm{C}$ and $\mathrm{Si}$, elemental $\mathrm{X}$-ray mapping has been used and the result is shown in Fig. 2d and 2e. The elemental X-ray maps of $\mathrm{C}$ and Si combined with the SE image (Fig. 2b) show that the electrochemically active Si particles are homogeneously dispersed and distributed on the graphite matrix. During high energy mechanical milling of graphite and silicon, it can be expected that the harder silicon particles gets fragmented and embedded within the graphite matrix.

Figure 3a shows the variation of gravimetric specific capacity $(\mathrm{mAh} / \mathrm{g})$ with cycle number for the Si/C + PVDF + SP composite electrode, made with 8 wt.\% PVDF binder, cycled at different current rates $(50 \mathrm{~mA} / \mathrm{g}$ to $200 \mathrm{~mA} / \mathrm{g})$ and an electrode loading of $3.0-3.5 \mathrm{mg} \mathrm{cm}^{-2}$. The $\mathrm{Si} / \mathrm{C}+\mathrm{PVDF}+\mathrm{SP}$ composite electrode cycled at $\sim 50 \mathrm{~mA} / \mathrm{g}$ for the $1^{\text {st }}$ two cycles shows a first discharge $\left(\mathrm{Li}^{+}\right.$alloying) and first charge $\left(\mathrm{Li}^{+}\right.$dealloying) capacity $\sim 990 \mathrm{mAh} / \mathrm{g}$ and $\sim 780 \mathrm{mAh} / \mathrm{g}$, respectively, with a first cycle irreversible (FIR) loss of 21\%. On the other hand, the $\mathrm{Si} / \mathrm{C}+\mathrm{PVDF}+\mathrm{SP}$ composite electrode cycled at $\sim 100 \mathrm{~mA} / \mathrm{g}\left(3^{\text {rd }}-6^{\text {th }}\right.$ cycle $)$ and $\sim 200 \mathrm{~mA} / \mathrm{g}\left(7^{\text {th }}-11^{\text {th }}\right.$ cycle) shows a reversible specific capacity $\sim 700 \mathrm{mAh} / \mathrm{g}$ and $\sim 620 \mathrm{mAh} / \mathrm{g}$, respectively (Fig. 3a). The differential capacity plot $(\mathrm{dQ} / \mathrm{dV} \quad v s$. V) of $\mathrm{Si} / \mathrm{C}+\mathrm{PVDF}+\mathrm{SP}$ composite electrode corresponding to the $1^{\text {st }}$ and $2^{\text {nd }}$ cycle cycled at $\sim 50 \mathrm{~mA} / \mathrm{g}$, shown in Fig. $\mathbf{3 b}$, shows that both $\mathrm{Si}$ and graphite are electrochemically active to $\mathrm{Li}$, as expected. The appearance of alloying peaks corresponding to $\sim 0.3 \mathrm{~V}, \sim 0.25 \mathrm{~V}$ and $\sim 0.09 \mathrm{~V}$ after the first cycle suggests the formation of $\mathrm{LiSi}$, $\mathrm{Li}_{7} \mathrm{Si}_{3}$ and $\mathrm{Li}_{3.16} \mathrm{Si}$, and amorphization of $\mathrm{Si}$ after the first cycle, as discussed in detail in our earlier papers [42]. In order to study the long term cyclability of the composite electrode, which primarily depends on the mechanical stability/integrity of the electrode structure as well as electrode impedance/resistance during repeated alloying and de-alloying processes, the $\mathrm{Si} / \mathrm{C}+\mathrm{PVDF}+\mathrm{SP}$ composite electrode is cycled for an additional 100 cycles at a current rate of 
$\sim 200 \mathrm{~mA} / \mathrm{g}$. The long term cyclability of the Si/C+PVDF+SP composite electrode, shown in Fig. 3a, reflects the degradation of the specific capacity with increasing cycle numbers (fade in capacity $\sim 0.22 \%$ per cycle), depicting a specific capacity $\sim 466 \mathrm{mAh} / \mathrm{g}$ after the $111^{\text {th }}$ cycle. The composite electrode also exhibits a coulombic efficiency $\sim 99.5 \%$ in the entire range of cycling. This fade in capacity likely arises due to partial mechanical degradation of the composite electrode caused by the degradation of the binder matrix rather than the failure of individual $\mathrm{Si} / \mathrm{C}$ particle and corresponding increase in the electrode resistance with cycling as measured by electrochemical impedance spectroscopy detailed later.

The SEM images before and after cycling of the composite electrode (shown in Fig. 4) shows no significant structural damage/mechanical disintegration of the composite electrode after cycling. However, the fine structural degradation or integrity of the binder cannot be unequivocally confirmed from these SEM images. In order to confirm and understand the molecular level degradation or integration of the PVDF matrix binder, the chemical structure of PVDF polymer before and after electrochemical cycling has been characterized by ${ }^{1} \mathrm{H}$ NMR. The ${ }^{1}$ H NMR spectrum of PVDF before cycling, shown in Fig. 5a, indicates a broad resonance in the range of $\delta \sim 2.8-3.0 \mathrm{ppm}$ corresponding to the PVDF polymer attributable to the head-to-tail (ht) bonding arrangements of the PVDF main chains, whereas the weaker chemical shift at $\delta \sim 2.25$ ppm is assigned to the head-to-head $(\mathrm{hh})$ or tail-to-tail $(\mathrm{tt})$ stereo-regularities $[43,44]$. The chemical shift at $\sim 2.50 \mathrm{ppm}$ corresponds to the residual DMSO- $\mathrm{d}_{6}$ signal. The broad resonance in the range of $\delta \sim 2.8-3.0 \mathrm{ppm}$ corresponding to PVDF is not seen after electrochemical cycling (Fig. 5b) which indicates possible degradation or permanent deformation of the low elastic modulus PVDF polymer during electrochemical cycling. The additional peaks at different $\delta$ values after electrochemical cycling (Fig. 5b) are expected to arise due to the presence of smaller degraded species of PVDF and/or other organic byproducts generated due to electrolyte decomposition on the surface of the electrode. This result clearly suggests the inferior structural characteristics of the PVDF based soft polymer binder rendering it clearly unfavorable as a polymer binder system for Si based anodes. The inferior stability and structural changes of PVDF following cycling depicted by the ${ }^{1} \mathrm{H}$ NMR analysis is indicative of the inability of PVDF to support the $\mathrm{Si} / \mathrm{C}$ nanocomposite particles resulting in failure of the $\mathrm{Si} / \mathrm{C}$ based electrodes 
system even with a low $\mathrm{Si}$ content exhibiting a specific capacity of only $\sim 600 \mathrm{mAh} / \mathrm{g}$ when cycled at $\sim 200 \mathrm{~mA} / \mathrm{g}$.

The ${ }^{1} \mathrm{H}$ NMR results indicate that the use of a higher modulus polymer would bode better and lead to likely better performance compared to PVDF. In order to improve the bond strength, and as a result, the tensile modulus of the polymeric binder, water soluble natural polymer PGG of higher elastic modulus and yield strength than PVDF (Table 1) is used to improve the cyclability of Si/C based composite electrode. Fig. 6 shows the variation in specific capacity versus cycle number of $\mathrm{Si} / \mathrm{C}+\mathrm{PGG}+\mathrm{SP}$ composite electrode with an identical active material loading of 3.0-3.5 mg cm $\mathrm{m}^{-2}$, fabricated with $8 \mathrm{wt} . \%$ water soluble PGG binder, cycled at different current rates $(50 \mathrm{~mA} / \mathrm{g}$ to $200 \mathrm{~mA} / \mathrm{g})$ but similar to the composite made with the PVDF binder discussed earlier. The $\mathrm{Si} / \mathrm{C}+\mathrm{PGG}+\mathrm{SP}$ composite cycled at $\sim 50 \mathrm{~mA} / \mathrm{g}$ for $1^{\text {st }}$ two cycle shows similar first discharge and first charge capacity $\sim 1006 \mathrm{mAh} / \mathrm{g}$ and $\sim 777 \mathrm{mAh} / \mathrm{g}$, respectively, with an irreversible loss of $23 \%$ in comparison with PVDF binder. The Si/C+PGG+SP composite electrode cycled at $\sim 100 \mathrm{~mA} / \mathrm{g}\left(3^{\text {rd }}-6^{\text {th }}\right.$ cycle $)$ and $\sim 200 \mathrm{~mA} / \mathrm{g}\left(7^{\text {th }}-11^{\text {th }}\right.$ cycle $)$ also shows comparable reversible capacity $\sim 700 \mathrm{mAh} / \mathrm{g}$ and $\sim 620 \mathrm{mAh} / \mathrm{g}$, respectively, in comparison to PVDF binder under identical conditions (Fig. 3a). The above results clearly suggests that the different physical/chemical properties of the composite electrode with PGG binder such as wettability/permeability of the electrolyte, Li ion transport, electronic conductivity is not affected by the PGG binder. However, the long term cyclability of the Si/C+PGG+SP composite electrode, shown in Fig. 6, clearly indicates improved cyclability (fade in capacity $\sim 0.04 \%$ per cycle) in comparison to the $\mathrm{Si} / \mathrm{C}+\mathrm{PVDF}+\mathrm{SP}$ composite electrode (fade in capacity $\sim 0.22 \%$ per cycle), and exhibits a capacity $\sim 600 \mathrm{mAh} / \mathrm{g}$ after $111^{\text {th }}$ cycle. Moreover, the $\mathrm{Si} / \mathrm{C}+\mathrm{PGG}+\mathrm{SP}$ composite electrode displays a coulombic efficiency $\sim 99.5 \%$ in the entire range of cycling.

${ }^{1} \mathrm{H}-\mathrm{NMR}$ studies of PGG containing electrode before and after cycling has also been performed to understand the structural stability of the binder. The ${ }^{1} \mathrm{H}-\mathrm{NMR}$ spectra of PGG before cell cycling is shown in Fig. 7a. The broad resonances in the region $\delta=3.0-4.2 \mathrm{ppm}$ are due to sugar protons and a peak at $\delta=4.7 \mathrm{ppm}$ corresponds to the anomeric protons, overlaid by the solvent peak $\left(\mathrm{D}_{2} \mathrm{O}-\mathrm{d}\right)[32]$. The ${ }^{1} \mathrm{H}-\mathrm{NMR}$ spectra after cell cycling (Fig. 7b) shows that PGG does not degrade (peaks are marked as $*$ ) even after $111^{\text {th }}$ cycle, which suggest that the high elastic modulus binder based on PGG can act as suitable binders in comparison to PVDF. The 
additional peaks at different $\delta$ values after electrochemical cycling (Fig. 7b) are expected to arise due to the presence of different dissolved organic byproducts generated due to decomposition of the electrolyte on the electrode surface that are likely soluble in the solvent used to extract the binder.

In order to understand the failure behavior of PVDF and PGG based binder electrode, electrochemical impedance spectroscopy of $\mathrm{Si} / \mathrm{C}+\mathrm{PVDF}+\mathrm{SP}$ and $\mathrm{Si} / \mathrm{C}+\mathrm{PGG}+\mathrm{SP}$ composite electrodes have been performed using $5 \mathrm{mV}$ AC amplitude at various stages of cycling to measure the change of interfacial and charge transfer resistance with cycling. A representative impedance curve obtained after the $80^{\text {th }}$ cycle of charge (Li-alloying at $1.2 \mathrm{~V}$ ) of $\mathrm{Si} / \mathrm{C}+\mathrm{PGG}+\mathrm{SP}$ composite electrode, shown in Fig. 8a, shows the characteristic three semi-circular arcs at high and medium frequency, and series resistance $\left(\mathrm{R}_{\mathrm{s}}\right)$ of $\sim 4-5 \Omega-\mathrm{cm}^{2}[11,43,44]$. The high frequency $1^{\text {st }}$ and $2^{\text {nd }}$ semi-circular arc is associated with interfacial impedance between the active material and current collector $\left(\mathrm{R}_{\mathrm{ec}}\right)$, and surface films due to the solid electrolyte interphase (SEI) formation between the electrode and electrolyte $\left(\mathrm{R}_{\text {film }}\right)$, respectively $[43,44]$. The combined impedance of $R_{e c}$ and $R_{\text {film }}$ has been denoted as interfacial resistance $\left(R_{i n t}=R_{e c}+R_{\text {film }}\right)$ in the present work. The $3^{\text {rd }}$ semi-circular arc in the medium frequency region corresponds to the electrode charge transfer resistance $\left(\mathrm{R}_{\mathrm{ct}}\right)[45,46]$. Low frequency Warburg type behavior $\left(\mathrm{W}_{\mathrm{o}}\right)$ is also observed corresponding to the solid-state Li diffusion. Randle's circuit model, shown in the inset of Fig. 8a, has been used to fit the curves in the Nyquist plots to obtain the $R_{s}, R_{\text {ec }}, R_{\text {film }}$, $\mathrm{R}_{\text {int }}\left(=\mathrm{R}_{\mathrm{ec}}+\mathrm{R}_{\text {film }}\right)$ and $\mathrm{R}_{\mathrm{ct}}$ resistances.

Figure 8b depict the Nyquist plot as well as fitted curve of the $\mathrm{Si} / \mathrm{C}+\mathrm{PVDF}+\mathrm{SP}$ electrodes and $\mathrm{Si} / \mathrm{C}+\mathrm{PGG}+\mathrm{SP}$ electrodes measured at open circuit potential (OCP). The experimental curve obtained at OCP has been fitted by considering $\mathrm{R}_{\mathrm{S}}$ and interfacial resistance $\left(\mathrm{R}_{\mathrm{i}}=\mathrm{R}_{\mathrm{ec}}+\mathrm{R}_{\mathrm{film}}\right)$ since $\mathrm{R}_{\mathrm{ec}}$ and $\mathrm{R}_{\text {film }}$ could not be distinguished as a separate arc, and the values of $\mathrm{R}_{\mathrm{s}}$ and $\mathrm{R}_{\mathrm{i}}$ are tabulated in Table 2. The electrochemical impedance spectroscopy of $\mathrm{Si} / \mathrm{C}$ composite with PVDF and PGG shows comparable interfacial resistance $\left(\mathrm{R}_{\mathrm{i}} \sim 200 \Omega-\mathrm{cm}^{2}\right)$ at OCP (Fig. 8b and Table 2). On the other hand, the impedance curve after $1^{\text {st }}$ discharge $\left(0.02 \mathrm{~V}-1^{\text {st }}\right.$ 
cycle) along with the fitted curve, shown in Fig. 8c, clearly shows reduction in the interfacial resistance $\left(\mathrm{R}_{\mathrm{i}}\right)$ in comparison to OCP (Table 2) as expected with the formation of lithium silicides during discharge. However, the interfacial resistance $\left(\mathrm{R}_{\mathrm{i}}\right)$, at $0.02 \mathrm{~V}$ in the discharged state, is lower for $\mathrm{Si} / \mathrm{C}+\mathrm{PGG}+\mathrm{SP}\left(75 \Omega-\mathrm{cm}^{2}\right)$ compared to $\mathrm{Si} / \mathrm{C}+\mathrm{PVDF}+\mathrm{SP}\left(97 \Omega-\mathrm{cm}^{2}\right)$ (Table 2) which suggests the formation of a larger interphase/SEI layer formation for the $\mathrm{Si} / \mathrm{C}+\mathrm{PVDF}+\mathrm{SP}$ composite electrode contrasted with that for the $\mathrm{Si} / \mathrm{C}+\mathrm{PGG}+\mathrm{SP}$ composite electrode. This result clearly suggests that the $\mathrm{Si} / \mathrm{C}+\mathrm{PVDF}+\mathrm{SP}$ composite electrode undergoes more degradation after the $1^{\text {st }}$ discharge than $\mathrm{Si} / \mathrm{C}+\mathrm{PGG}+\mathrm{SP}$ composite electrode. Figures $8 d, 8 \mathrm{e}$ and $8 f$ depict the Nyquist plots along with fitted curves for the $\mathrm{Si} / \mathrm{C}+\mathrm{PVDF}+\mathrm{SP}$ electrodes and $\mathrm{Si} / \mathrm{C}+\mathrm{PGG}+\mathrm{SP}$ electrodes after the $1^{\text {st }}$ charge $\left(1.2 \mathrm{~V}-1^{\text {st }}\right.$ cycle $)$, after the $20^{\text {th }}$ cycle charge $(1.2 \mathrm{~V}-$ $20^{\text {th }}$ cycle) and after the $40^{\text {th }}$ cycle charge $\left(1.2 \mathrm{~V}-40^{\text {th }}\right.$ cycle $)$, respectively. Table 2 lists the values of $R_{s}, R_{i}=R_{\text {film }}+R_{e c}$ and $R_{c t}$ obtained from the fitted curves. It can be noticed that the $R_{i}$ decreases upon further delithiation after the $1^{\text {st }}$ cycle (Table 2) and remains constant with increase in cycle numbers. The interfacial resistance after de-alloying of $\mathrm{Li}$ at $1.2 \mathrm{~V}$ after the $1^{\text {st }}$ cycle, $20^{\text {th }}$ cycle and $40^{\text {th }}$ cycle also shows that the $\mathrm{Si} / \mathrm{C}+\mathrm{PGG}+\mathrm{SP}$ exhibits lower interfacial resistance ( $\left.\sim 10-12 \mathrm{ohm}-\mathrm{cm}^{2}\right)$ in comparison to the $\mathrm{Si} / \mathrm{C}+\mathrm{PVDF}+\mathrm{SP}$ composite electrode $(\sim 25-27$ ohm- $\mathrm{cm}^{2}$ ) (Table 2) which shows the effectiveness of the PGG binder for the $\mathrm{Si} / \mathrm{C}$ electrochemically active composite materials. In addition, it has been noticed that the charge transfer resistance $\left(\mathrm{R}_{\mathrm{ct}}\right)$ of $\mathrm{Si} / \mathrm{C}+\mathrm{PVDF}+\mathrm{SP}$ increases with cycle numbers while the $\mathrm{R}_{\mathrm{ct}}$ values of $\mathrm{Si} / \mathrm{C}+\mathrm{PGG}+\mathrm{SP}$ remains almost constant at $\sim 8-9 \mathrm{ohm} \mathrm{cm}^{2}$ (Table-2). At the same time, the $\mathrm{R}_{\mathrm{ct}}$ values of $\mathrm{Si} / \mathrm{C}+\mathrm{PVDF}+\mathrm{SP}$ are higher than $\mathrm{Si} / \mathrm{C}+\mathrm{PGG}+\mathrm{SP}$. The higher interfacial and charge transfer resistance of PVDF binder probably arises due to the structural failure of PVDF based electrodes whereas PGG shows low interfacial and charge transfer resistances due to better structural integrity with cycle numbers based on the EIS and ${ }^{1} \mathrm{H}$ NMR analyses.

The above results clearly suggest that the binders based on PGG, exhibiting high elastic modulus (Table 1), is useful to improve the mechanical properties of the composite electrode and consequently, the cyclability of $\mathrm{Si} / \mathrm{C}$ based Li-ion active system. In this regard, the PGG binder exhibiting potentially improved structural integrity of the composite electrode can be named as "mechanical integrity binder (MIB)" whereas the binder used to bind the particles without significant improvement in mechanical properties can be named as a "cohesive binder (CB)" (e.g. PVDF). In order to keep the integrity of the composite electrode structure of Si/C 
based systems, the generated strain/stress on $\mathrm{Si} / \mathrm{C}$ particles during alloying and de-alloying processes must be transmitted to the mechanical integrity binder without delamination in such a manner that the strain on the binder $\left(\varepsilon_{\mathrm{b}}\right)$ is equal to the strain of the $\mathrm{Si} / \mathrm{C}$ particle $\left(\varepsilon_{\mathrm{Si} / \mathrm{C}}\right)$ and the composite $\left(\varepsilon_{\mathrm{com}}\right)\left(\varepsilon_{\mathrm{com}}=\varepsilon_{\mathrm{b}}=\varepsilon_{\mathrm{Si} / \mathrm{C}}\right)$. In the iso-strain condition, the elastic modulus $\left(\mathrm{E}_{\mathrm{com}}\right)$ and breaking strength $\left(\sigma_{\text {com.b }}\right)$ of the composite electrode will depend on the volume fraction, elastic modulus, breaking strength of the binder and dispersoid Si/C particles following the Halpin-Tsai equation which can predict the micromechanics of particulate composite [31]. The mechanical integrity binder with higher elastic modulus will result in a composite electrode of higher elastic modulus and higher strength. However, it must be mentioned that the stress/strain experienced by the composite electrode $\left(\sigma_{\text {com }} / \varepsilon_{\text {com }}\right)$ must be within the elastic limit $\left(\sigma_{\text {com }}<\sigma_{\text {com.b }}\right)$ to avoid disintegration due to plastic or permanent deformation and consequent degradation of the composite electrode. In order to achieve minimum stress/strain (within the elastic limit) with suitable elastic modulus of the composite electrode with non-permanent deformation, a novel structural design along with suitable mechanical binder integrity needs to be explored. In the present study, it has been identified that the PGG based polymer of elastic modulus $\sim 3200 \mathrm{MPa}$ is likely a suitable polymer belonging to the mechanical integrity binder family for $\mathrm{Si} / \mathrm{C}$ based anode of low Si content exhibiting a specific capacity $\sim 600 \mathrm{mAh} / \mathrm{g}$ (at $\sim 200 \mathrm{~mA} / \mathrm{g}$ ), since the composite electrode stress/strain is expected to be within the elastic deformation region. In addition to improving the mechanical properties, recent investigations have also revealed that the polymeric binders containing carboxylic acid and/or hydroxyl functional groups may improve the cycling performance utilizing hydrogen bonding interactions with the Si active system [2026]. It must be mentioned here that the high elastic modulus composite electrode also has the disadvantage of being brittle once the stress/strain reaches above breakpoint strength/strain level $\left(\sigma_{\text {com }}>\sigma_{\text {com.b }}\right)$. It has also been identified by the present authors (data not shown) that the stiff high elastic modulus polymer binder (e.g. PGG) is not suitable for $\mathrm{Si} / \mathrm{C}$ composite with high $\mathrm{Si}$ content $\mathrm{Si} / \mathrm{C}$ system (specific capacity $\geq 1200 \mathrm{mAh} / \mathrm{g}$ at $100 \mathrm{~mA} / \mathrm{g}$ ) which is expected to exhibit higher mechanical stress/strain on the composite. For higher Si content composite electrode, a blend polymer with higher mechanical properties than the parent polymers needs to be developed. The electrochemical performance of Si/C system based on such blend polymers is currently being explored in the authors' laboratory and the cyclability results will be published in a subsequent publication. 


\section{Conclusion}

The effect of mechanical properties of a mechanical integrity binder on the structural stability and long term cyclability of $\mathrm{Si} / \mathrm{C}$ based active materials for $\mathrm{Li}$-ion batteries has been studied. Binders belonging to the mechanical integrity binder (MIB) class used for electrode manufacturing processes not only helps to bind the electro-active particles together but is also expected to likely improve the overall mechanical properties of the composite electrode. In the present investigation, two different polymeric binders of different mechanical properties (e.g. elastic modulus, yield strength) have been studied to correlate the cyclability of the composite electrode with the mechanical properties of the binder. In this regard, PVDF of elastic modulus $\sim 1000 \mathrm{MPa}$, and a novel new polymer family namely, Guar Gum of elastic modulus $\sim 3200 \mathrm{MPa}$ has been chosen and explored as a suitable binder for $\mathrm{Si} / \mathrm{C}$ system. The $\mathrm{Si} / \mathrm{C}$, obtained after mechanical milling of Si, Gr, and PAN of nominal composition Gr-14wt.\% Si-30wt.\% PAN followed by thermal treatment at $973 \mathrm{~K}$ in UHP-Ar atmosphere, exhibits a specific capacity $\sim 780 \mathrm{mAh} / \mathrm{g}$ and $\sim 620 \mathrm{mAh} / \mathrm{g}$ at charge/discharge rate of $\sim 50 \mathrm{~mA} / \mathrm{g}$ and $\sim 200 \mathrm{~mA} / \mathrm{g}$, respectively, irrespective of the binder suggesting that the chosen binder does not affect the Li-ion diffusivity, permeability of electrolyte, electronic conductivity, and other physical properties which can adversely affect the battery performance. However, it has been identified that the long term cyclability of $\mathrm{Si} / \mathrm{C}$ system depends largely on the binder mechanical properties. Accordingly, the high elastic modulus PGG shows better cyclability than low elastic modulus PVDF binder indicating that the mechanical stress/strain generated within the composite electrode with PGG binder is within the elastic regime. The ${ }^{1} \mathrm{H}-\mathrm{NMR}$ based molecular structural studies of the polymer binders before and after cycling have confirmed that structural degradation of the low elastic modulus PVDF after cycling ensues, whereas the high elastic modulus PGG shows no such permanent deformation or structural damage. These results indicate and suggest that the high elastic modulus PGG based polymer is indeed a promising binder family for $\mathrm{Si} / \mathrm{C}$ based anode that is worthy of further detailed examination in a full cell assembly.

\section{Author contribution}


M.K.D., R. K. and P. N. K devised the original concept and designed the experiments. R. K. and M. K. D. synthesized the materials, prepared the electrodes and performed the electrochemical characterization. K. D. conducted the ${ }^{1}$ H-NMR and analyzed the NMR data. M.K. D. and P. H. J. collect and analyzed the impedance data. R.K, B. G., P. M. S, P. P. and S. D. performed SEM and XRD analyses. M. K. D., R. K., K. D., P. H. J. and P. N. K. analyzed the data and wrote the first draft of the paper; and all authors participated in the manuscript revision. The project is conceived and supervised by P.N.K.

\section{Acknowledgements}

The authors gratefully acknowledge the financial support provided by the Assistant Secretary for Energy Efficiency and Renewable Energy (EERE), Office of Vehicle Technologies of the U.S. Department of Energy under Contract DE-AC02-05CH1123, Subcontract No. 6951369 under the Batteries for Advanced Transportation Technologies (BATT) program, the National Science Foundation (NSF-CBET-0933141) and partial support of the Ford Foundation. PNK also acknowledges the Edward R. Weidlein Chair Professorship funds and the Center for Complex Engineered Materials (CCEMM) for partial support of this research.

\section{References:}

[1] Electrochemical Energy Storage Technical Team Road Map, USDRIVE, Driving Research and Innovation for Vehicle Efficiency and Energy Sustainability, June, 2013.

[2] Basic Research Needs for Electrical Energy Storage (Office of Basic Energy Science, US Department of Energy, Washington, DC, 2007).

[3] M. M. Thackeray, C. Wolvertone, E. D. Isaacs, Energy Environ. Sci., 5 (2012) 7854.

[4] EV everywhere Grand challenge blueprint, US department of Energy, January 31, 2013.

[5] R. Teki, M. K. Datta, R. Krishnan, T. C. Parker, T. M. Lu, P. N. Kumta and N. Koratkar, Small, 5 (2009) 2236. 
[6] X. Su, Q. L. Wu, J. C. Li, X. C. Xiao, A. Lott, W. Q. Lu, B. W. Sheldon, J. Wu, Advanced Energy Mater. 4 (2014) 1300882.

[7] W. Wang, P. N. Kumta, ACS Nano 4 (2010) 2233.

[8] M. H. Park, M. G. Kim, J. Joo, K. Kim, J. Kim, S. Ahn, Y. Cui, J. Cho, Nano Lett. 9 (2009) 3844.

[9] N. Liu, Z. Lu, J. Zhao, M. T. McDowell, H. W. Lee, W. Zhao, Y. Cui, Nature Nanotechnology 9 (2014) 187-192.

[10] M. K. Datta, J. Maranchi, S. J. Chung, R. Epur, K. Kadakia, P. Jampani, P. N. Kumta, Electro. Acta. 56 (2011) 4717.

[11] R. Epur, M. Ramanathan, M. K. Datta, D. Hong, P. H. Jampani, B. Gattu, P. N. Kumta, Nanoscale 7 (2015) 3504-3510.

[12] X. H. Liu, H. Zheng, L. Zhong, S. Huan, K. Karki, L. Q. Zhang, Y. Liu, A. Kushima, W. T. Liang, J. W. Wang, Nano Letters 11 (2011) 3312-3318.

[13] X. H. Liu, L. Zhong, S. Hunag, S. X. Mao, T. Zhu, J. Y. Hunag, ACS Nano 6 (2012) 15221531.

[14] M. J. Chon, V. A. Sethuraman, A. McCormick, V. Srinivasan, P. R. Guduru, Phys. Rev. Lett. 107 (2011) 0455031-0455034,

[15] A. Mukhopadhaya, B. W. Sheldon, Prog. Mater. Sci. 63 (2014) 58.

[16] M. K. Datta, P. N. Kumta, J. Power Sources 158 (2006) 557.

[17] Q. Xiao, Q. Zhang, Y. Fan, X. Wang, R. A. Susantyoko, Energy Enviorn. Sci. 7 (2014) 2261.

[18] M. Osiak, H. Geaney, E. Armstrong, C. O’Dwyer, J. Mater. Chem. A, 2 (2014) 9433. 
[19] N. Liu, H. Wu, M. T. McDowell, Y. Yao, C. M. Wang, Y. Cui, Nano Lett. 12 (2012) 33153321.

[20] J. Li, R. B. lewis, J. R. Dahn, Electroche. Solid State Lett. 10 (2007) A17.

[21] A Magasinski, B. Zdyrko, I. Kovalenko, B. Hertzberg, R. Burtovyy, C. F. Huebner, T. F. Fuller, I. Luzinov, G. Yushin, Appl. Mater. Interfaces 2 (2010) 3004.

[22] B. Liang, Y. Liu, Y. Xu, J. Power Sources 267 (2014) 469.

[23] M. Wu, X. Xiao, N. Vukmirovic, S. Xun, P. K. Das, X. Song, P. O. Velasco, D. Wang, A. Z. Weber, L. W. Wang, V. S. Battaglia, W. Yang, G. Liu, J. Am. Chem. Soc. 135 (2013) 12048.

[24] N. Yuca, H. Zhao, X. Song, M. F. Dogdu, W. Yuan, Y. Fu, V. S. Battaglia, X. Xiao, G. Liu, Appl. Mater. Interfaces 6 (2014) 17111.

[25] C. Kim, J. Y. Jang, N. S. Choi, S. Park, RSC Adv. 4 (2014) 3070.

[26] I. Kovalenko, B. Zdyrko, A Magasinski, B. Hertzberg, Z. Milicev, R. Burtovyy, I. Luzinov, G. Yushin, Science. 334 (2011) 75.

[27] J. Maranchi, O. Velikokhatnyi, M. K. Datta, I. Kim, P. N. Kumta, Ceramic Materials for Liion battery Applications, edited by B. Lee, S. Komarneni, "Chemical Processing of Ceramics", $2^{\text {nd }}$ edn., CRC press, Taylor and Francis, Boca Raton, Fl, 2005, pp: 667-711.

[28] Lithium ion batteries, edited by M. Yoshio, R. J. Brodd, A. Kozawa, Springer, NY. USA, 2009

[29] J. Liu, Q. Zhang, Z. Y. Wu, J. H. Wu, J. T. Li, L. Hunag, S. G. Sun, Chem. Commun. 50 (2014) 6386.

[30] Y. K. Jeong, T. W. Kwon, I. Lee, T. S. Kim, A. Coskun, J. W. Choi, Nano Lett. 14 (2014) 864. 
[31] J. C. Halpin, J. L. Kardos, Poly. Engg. Sci. 16 (1976) 344.

[32] G. Dodi, D. Hritcu, M. I. Popa, Cellulose Chem. Technol. 45 (2011) 171. http://www.ashland.com/Ashland/Static/Documents/AAFI/PRO_250-61_Guar.pdf.

[33] R. Murali, P. Vidhya, P. Thanikaivelan, Carbohydrate Polymers 110 (2014) 440.

[34] J. Liu, Q. Zhang, T. Zhang, J. T. Li, L. Huang, S. G. Sun, Adv. Funct. Mater. 25 (2015) 3599.

[35] M. K. Dufficy, S. A. Khan, P. S. Fedkiw, Mater. Chem. A. 3 (2015) 12023.

[36] M. K. Datta, P. N. Kumta, J. Power Sources 194 (2009) 1043.

[37] L. R. P. Cunha, C. M. R. de Pula, J. P. A. Feitosa, Int. J. Biol. Macromol. 41 (2007) 324.

[38] B. E. E. Mohajir, N. Heymans, Polymer 42 (2001) 7017. www.kynar.com.

[39] R. S. Banegas, C.F. Zornio, A. M. G. Borges, L. C. Porto, V. Soldi, Polímeros, 23 (2013) 182.

[40] M.A. Shenoy, D.J. D’Melo, Poly. Engg. Sci. 48 (2008) 124.

[41] A. L. Gomes, M. B. P. Zakia, J. G. Filho, E. Armelin, C. Aleman, J. S. C. Camposa, Polym. Chem 3 (2012) 1334.

[42] M. K. Datta, P. N. Kumta, J. Power Sources 165 (2007) 368.

[43] K. K. Jana, N. K. Vishwakarma, B. Ray, S. A. Khan, D. A. Avasthi, M. Misra, P. Maiti, RSC Advances 3 (2013) 6147.

[44] T. Cai, R. Wang, K. G. Neoh, E. T. Kang, Polym. Chem. 2 (2011) 1849.

[45] D. Aurbach, J. Power Sources 89 (2000) 206-218.

[46] J. Guo, A. Suna, X. Chena, C. Wang, A. Manivannan, Electro. Acta. 56 (2011) 3981. 
Table -1: Molecular weight and mechanical properties such as tensile modulus (E), tensile yield strength $\left(\sigma_{\mathrm{y}}\right)$ and elongation at break $\left(\varepsilon_{\mathrm{f}}\right)$ of PVDF and PGG polymeric binder $[32,33,38-40]$.

\begin{tabular}{|l|l|l|l|l|}
\hline Polymer & $\mathbf{M}_{\mathbf{w}}$ & $\mathbf{E}(\mathbf{M P a})$ & $\sigma_{\mathbf{y}}(\mathbf{M P a})$ & $\varepsilon_{\mathbf{f}}(\boldsymbol{\%})$ \\
\hline PVDF & 534,000 & $700-1200$ & $20-35$ & $150-350$ \\
\hline PGG & $1,000,000-2,000,000$ & $3000-3700$ & $32-48$ & $2-4$ \\
\hline
\end{tabular}

Table 2: Evolution of interfacial resistance and charge-transfer resistance of $\mathrm{Si} / \mathrm{C}+\mathrm{PVDF}+\mathrm{SP}$ composite electrodes and $\mathrm{Si} / \mathrm{C}+\mathrm{PGG}+\mathrm{SP}$ composite electrodes with cycling.

\begin{tabular}{|c|c|c|c|c|c|c|}
\hline & \multicolumn{2}{|c|}{$\mathbf{R}_{\mathbf{s}}\left(\mathbf{\Omega}-\mathbf{c m}^{2}\right)$} & \multicolumn{2}{c|}{$\mathbf{R}_{\mathbf{i}}\left(\mathbf{\Omega}-\mathbf{c m}^{2}\right)$} & \multicolumn{2}{c|}{$\mathbf{R}_{\mathbf{c t}}\left(\mathbf{\Omega}-\mathbf{c m}^{2}\right)$} \\
\cline { 2 - 7 } & PVDF & PGG & PVDF & PGG & PVDF & PGG \\
\hline OCP & 2.06 & 2.39 & 188.30 & 190.30 & - & - \\
\hline $0.01 \mathrm{~V}-1^{\text {st }}$ cycle & 2.37 & 1.63 & 96.17 & 74.66 & - & - \\
\hline $1.2 \mathrm{~V}-1^{\text {st }}$ cycle & 2.24 & 3.73 & 25.67 & 12.08 & 9.08 & 9.20 \\
\hline $1.2 \mathrm{~V}-20^{\text {th }}$ cycle & 5.99 & 2.74 & 25.27 & 11.02 & 10.04 & 8.22 \\
\hline $1.2 \mathrm{~V}-40^{\text {th }}$ cycle & 2.51 & 3.48 & 25.03 & 11.28 & 14.07 & 8.09 \\
\hline
\end{tabular}




\section{Figures Caption:}

Fig. 1: FTIR spectra of commercial PVDF and purified Guar Gum (PGG) along with their chemical structures.

Fig. 2: (a) XRD patterns of 50wt.\% Gr-20wt.\% Si-30wt.\% PAN after 10h of milling, and after thermal treatment of mechanically milled powder at $973 \mathrm{~K}$ for $6 \mathrm{~h}$ under UHP-Ar atmosphere. SEM secondary electron image (b), EDAX spectra of Si/C composite (c) showing the presence of $\mathrm{Si}, \mathrm{C}$ and $\mathrm{Fe}$, (d) X-ray elemental map of $\mathrm{C}$ and (e) $\mathrm{Si}$ of $\mathrm{Si} / \mathrm{C}$ composite.

Fig. 3: (a) Specific capacity $v$ s. cycle number of $\mathrm{Si} / \mathrm{C}+\mathrm{PVDF}+\mathrm{SP}$ composite electrode cycled at a constant current of $\sim 50 \mathrm{~mA} / \mathrm{g}, 100 \mathrm{~mA} / \mathrm{g}$ and $200 \mathrm{~mA} / \mathrm{g}$ in the potential window $0.02 \mathrm{~V}-1.2 \mathrm{~V}$ showing the long term cycling response. (b) Differential capacity vs. cell potential curves of $\mathrm{Si} / \mathrm{C}+\mathrm{PVDF}+\mathrm{SP}$ composite electrode obtained after $1^{\text {st }}$ and $2^{\text {nd }}$ cycle cycled at $\sim 50 \mathrm{~mA} / \mathrm{g}$ in the potential window of $0.02-1.2 \mathrm{~V}$.

Fig. 4: SEM micrograph of Si/C+PVDF+SP composite electrode (a) before and (b) after cycling for 111 cycles.

Fig. 5: ${ }^{1} \mathrm{H}-\mathrm{NMR}$ spectra of PVDF (a) before and (b) after cycling for 111 cycles in DMSO-d 6 .

Fig. 6: Specific capacity vs. cycle number of $\mathrm{Si} / \mathrm{C}+\mathrm{PGG}+\mathrm{SP}$ composite electrode cycled at current rates of $50 \mathrm{~mA} / \mathrm{g}-200 \mathrm{~mA} / \mathrm{g}$ in the potential window of $0.02-1.2 \mathrm{~V}$.

Fig. 7: ${ }^{1} \mathrm{H}-\mathrm{NMR}$ spectra of PGG (a) before and (b) after cycling for 111 cycles in $\mathrm{D}_{2} \mathrm{O}$. 
Fig. 8: A representative electrochemical impedance spectroscopy (a) of Si/C+PGG+SP after $80^{\text {th }}$ cycle of charge shows the characteristic impedance at high, medium and low frequency region. Electrochemical impedance spectroscopy of $\mathrm{Si} / \mathrm{C}+\mathrm{PVDF}+\mathrm{SP}$ and $\mathrm{Si} / \mathrm{C}+\mathrm{PGG}+\mathrm{SP}$ composite electrode b) at open circuit potential, c) after $1^{\text {st }}$ discharge at $\sim 0.02 \mathrm{~V}, \mathrm{~d}$ ) after $1^{\text {st }}$ cycle charge at $1.2 \mathrm{~V}$, e) after $20^{\text {th }}$ cycle charge at $1.2 \mathrm{~V}$, and f) after $40^{\text {th }}$ cycle charge at $1.2 \mathrm{~V}$. 


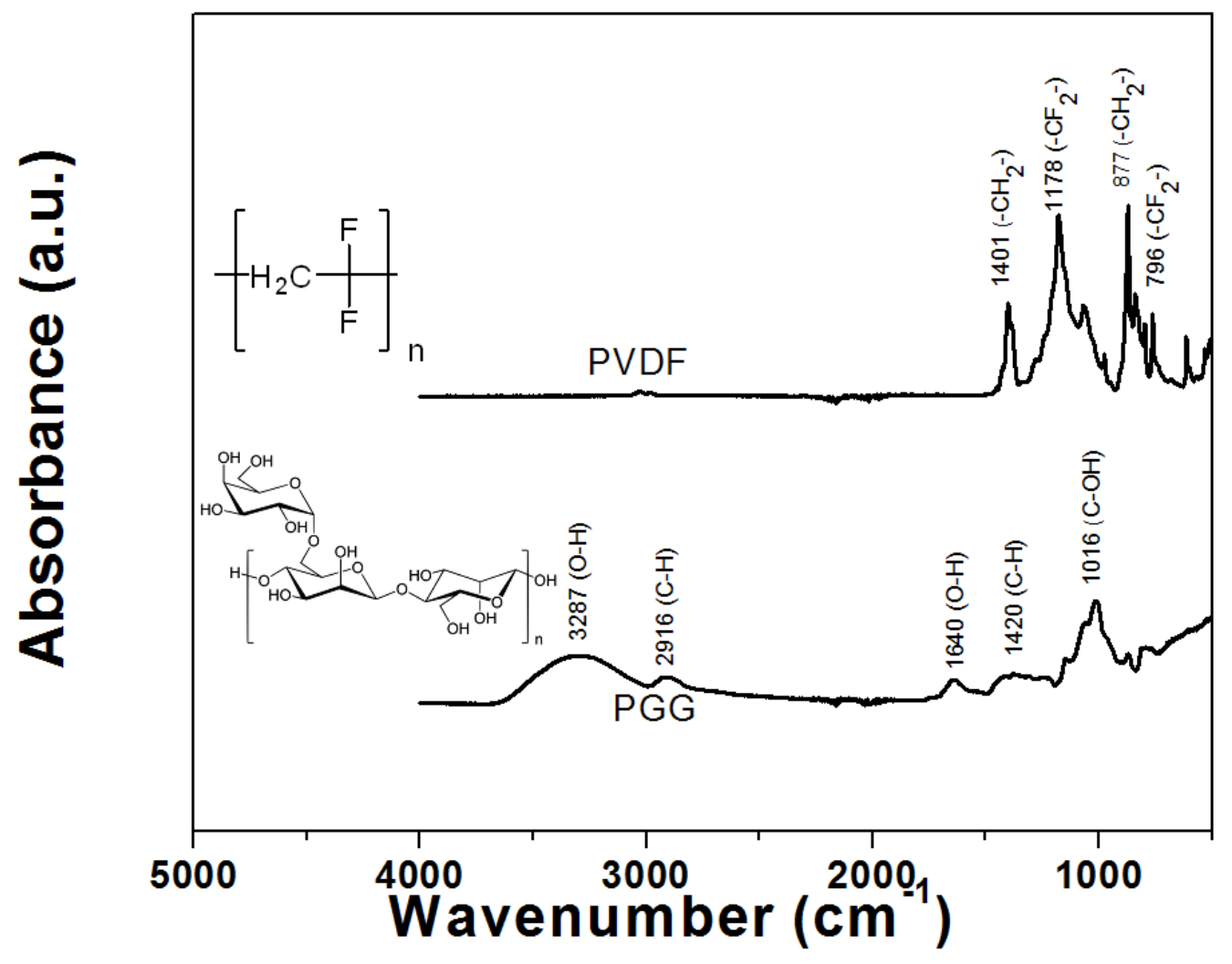




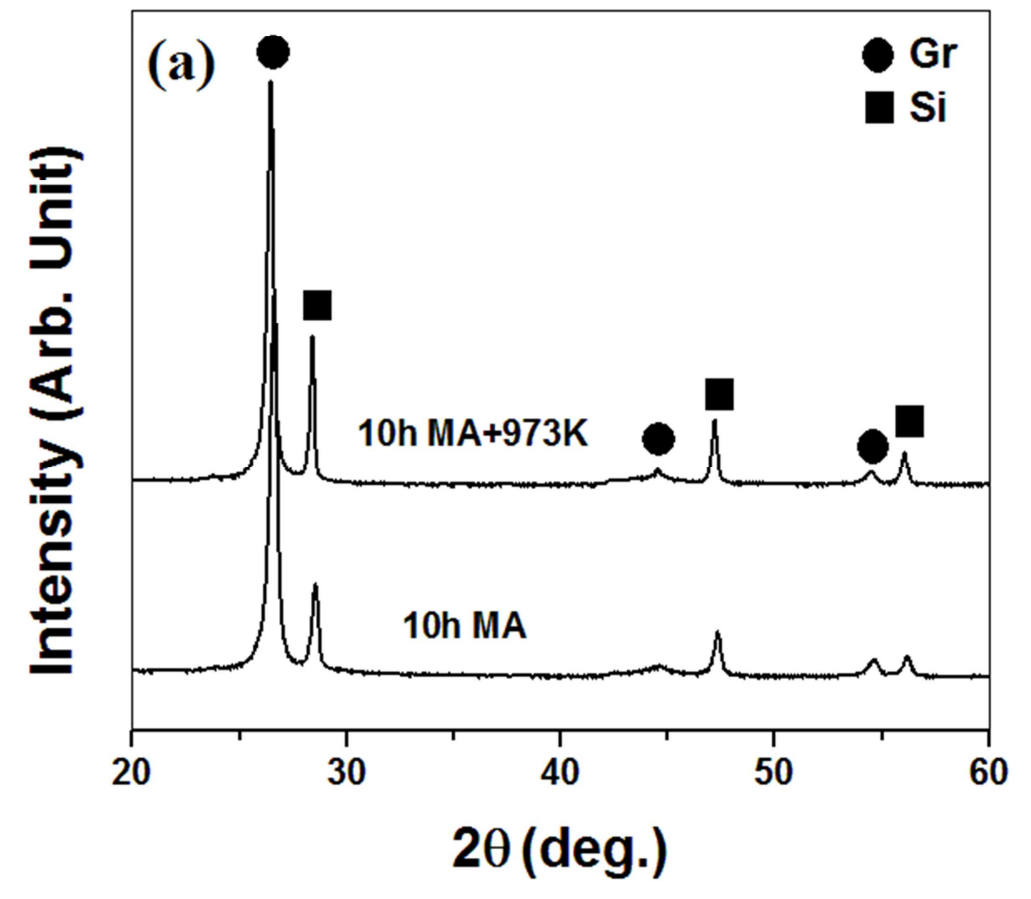




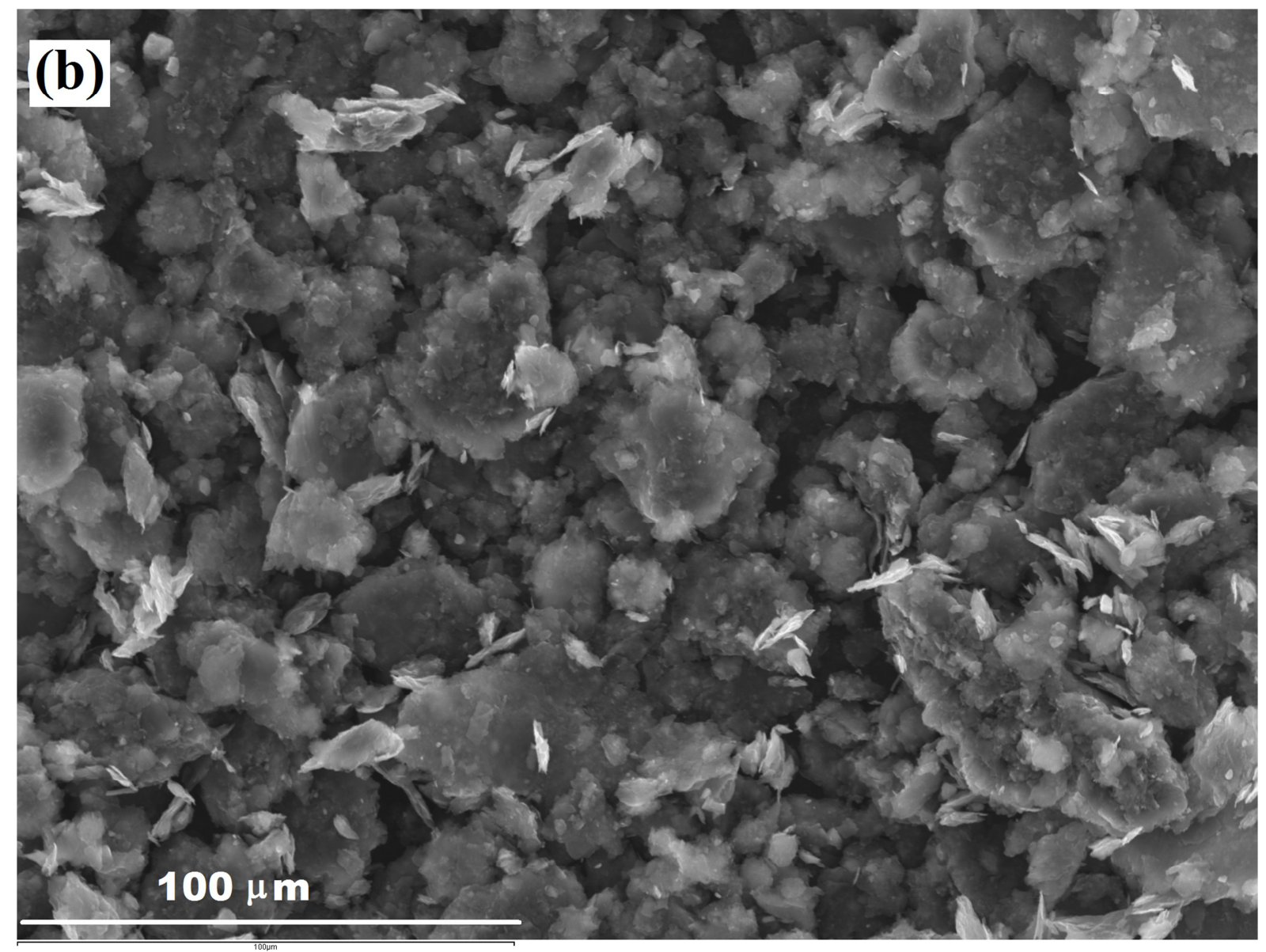




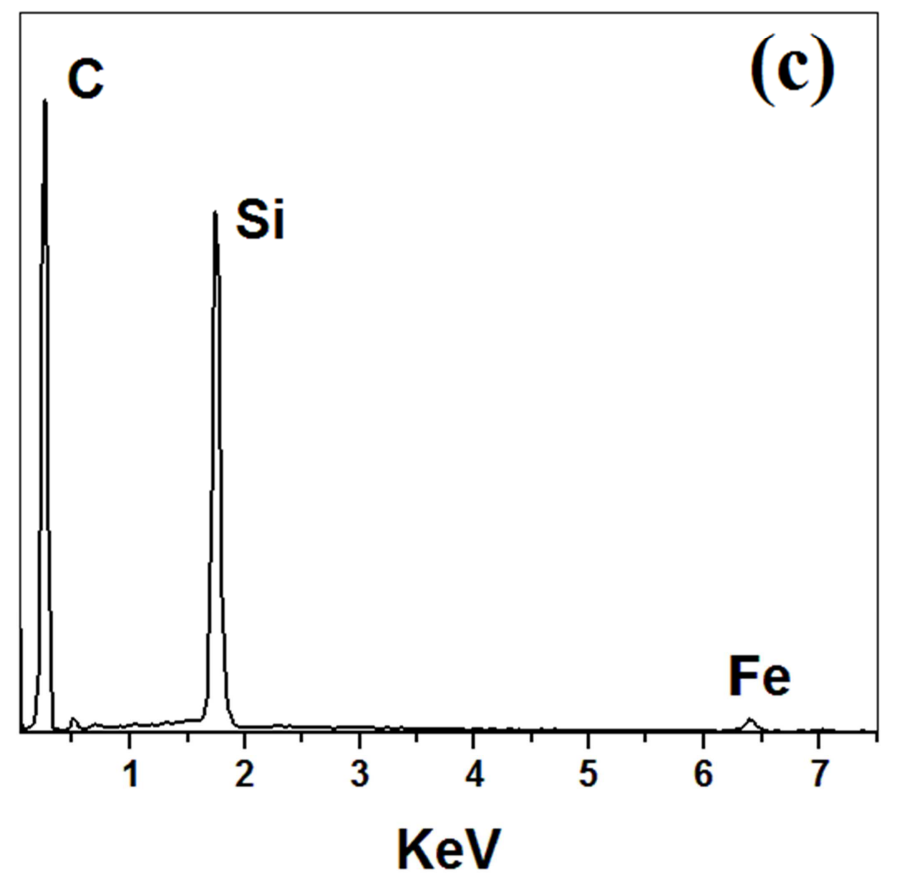




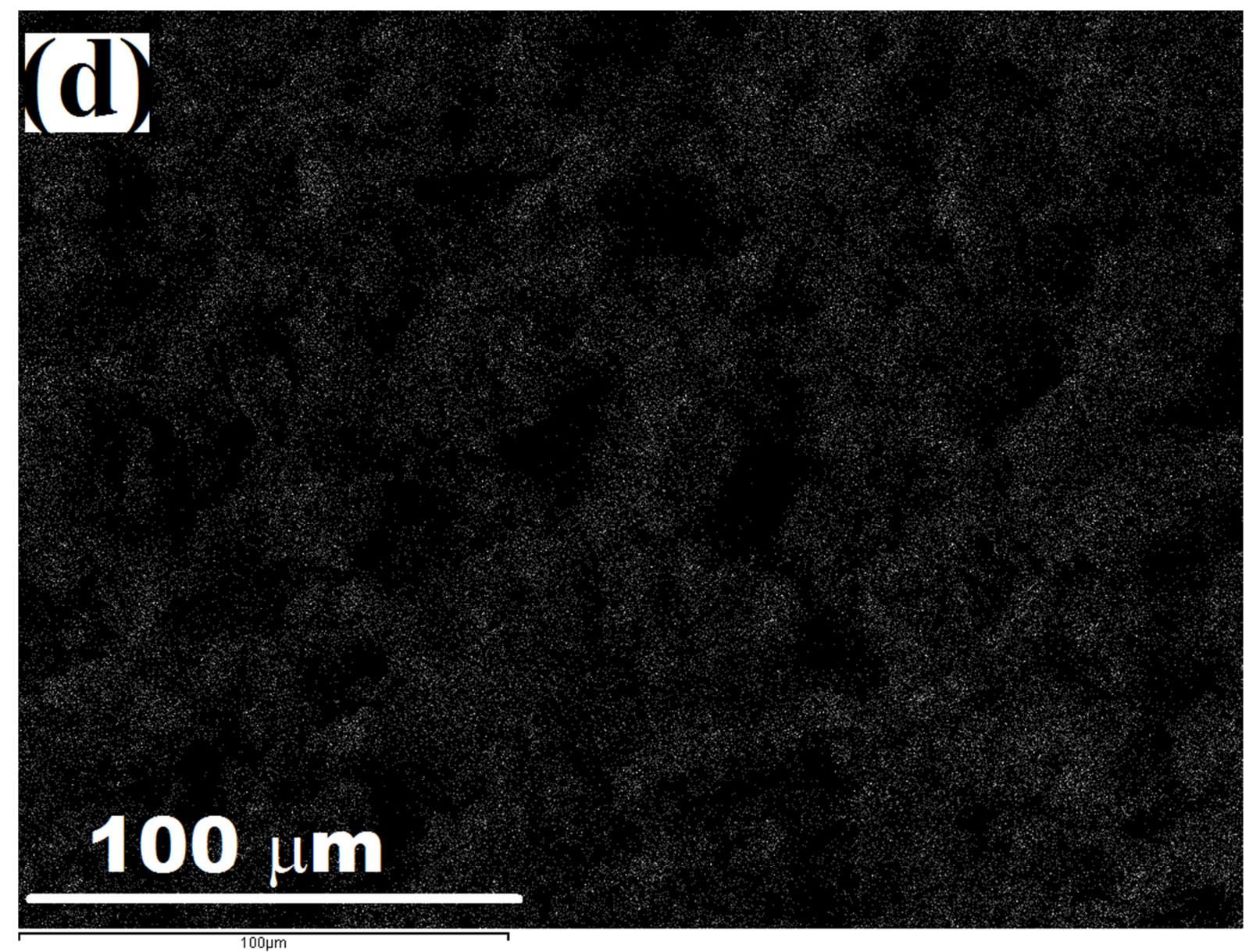




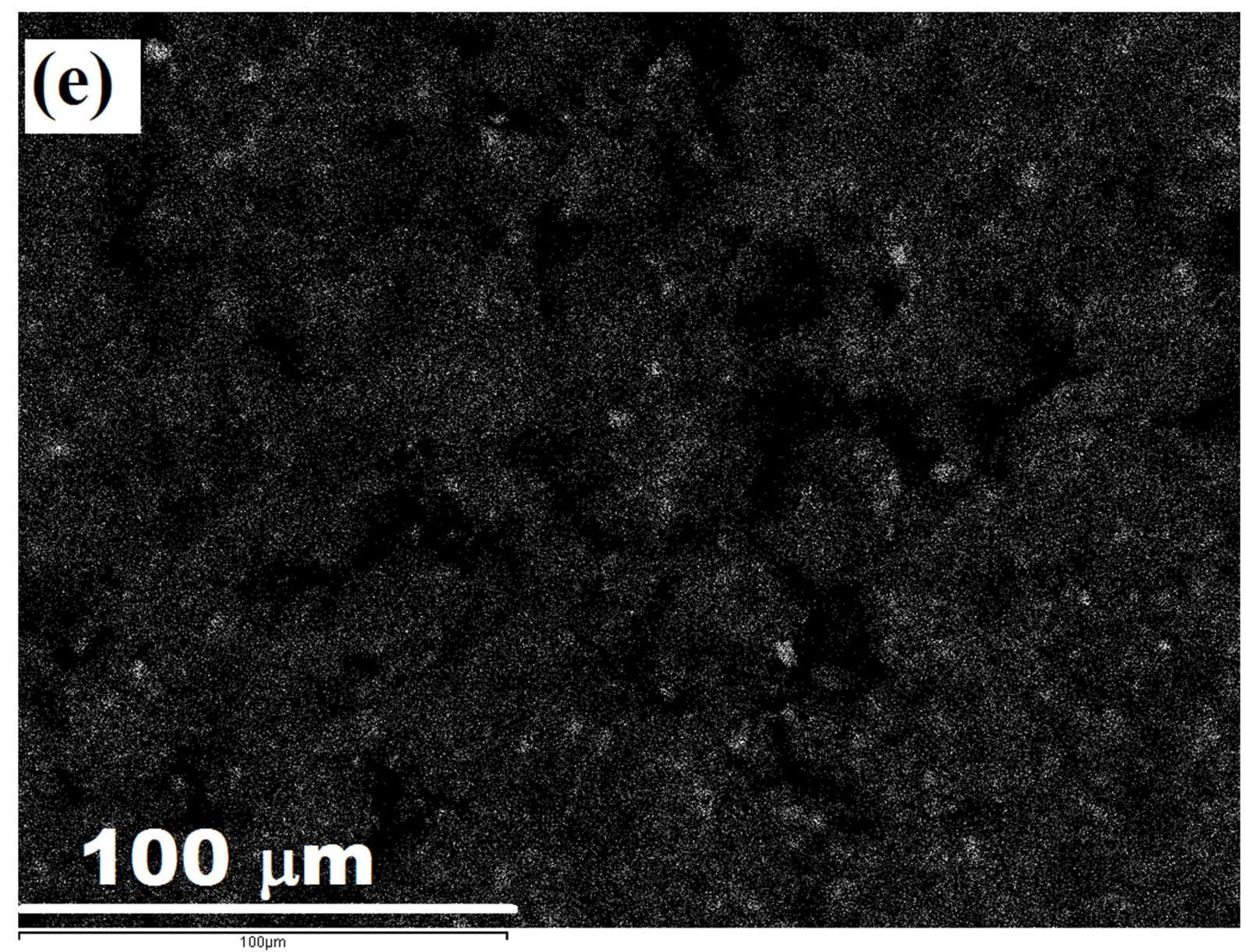




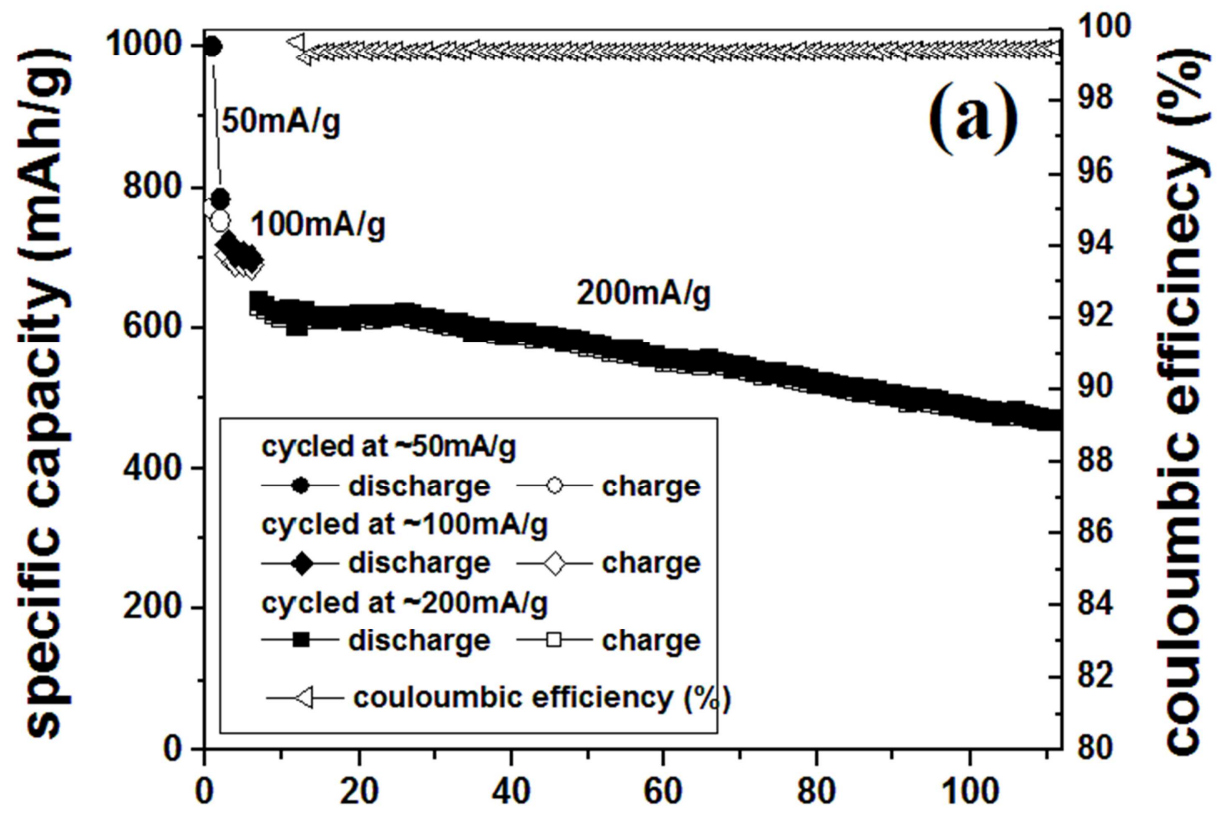

cycle number 


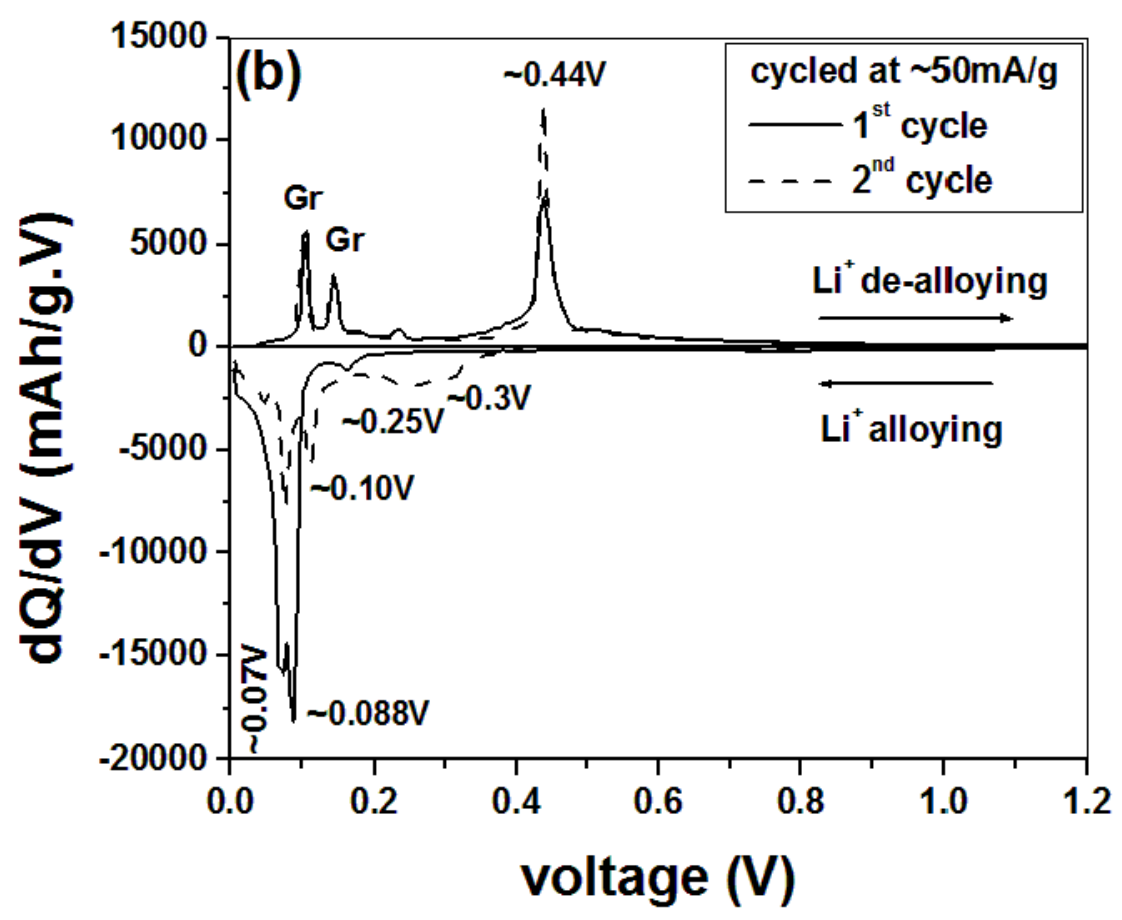




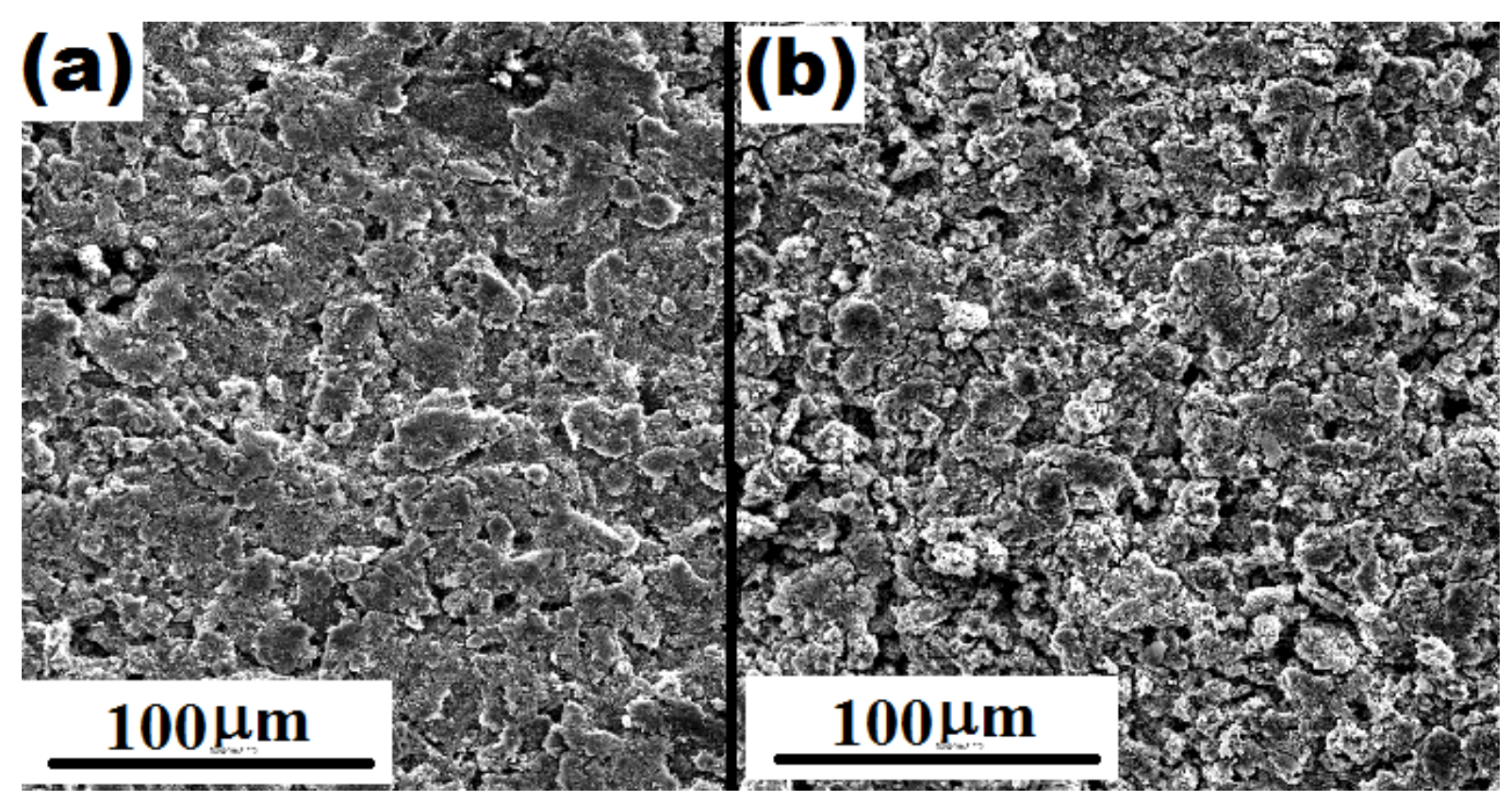




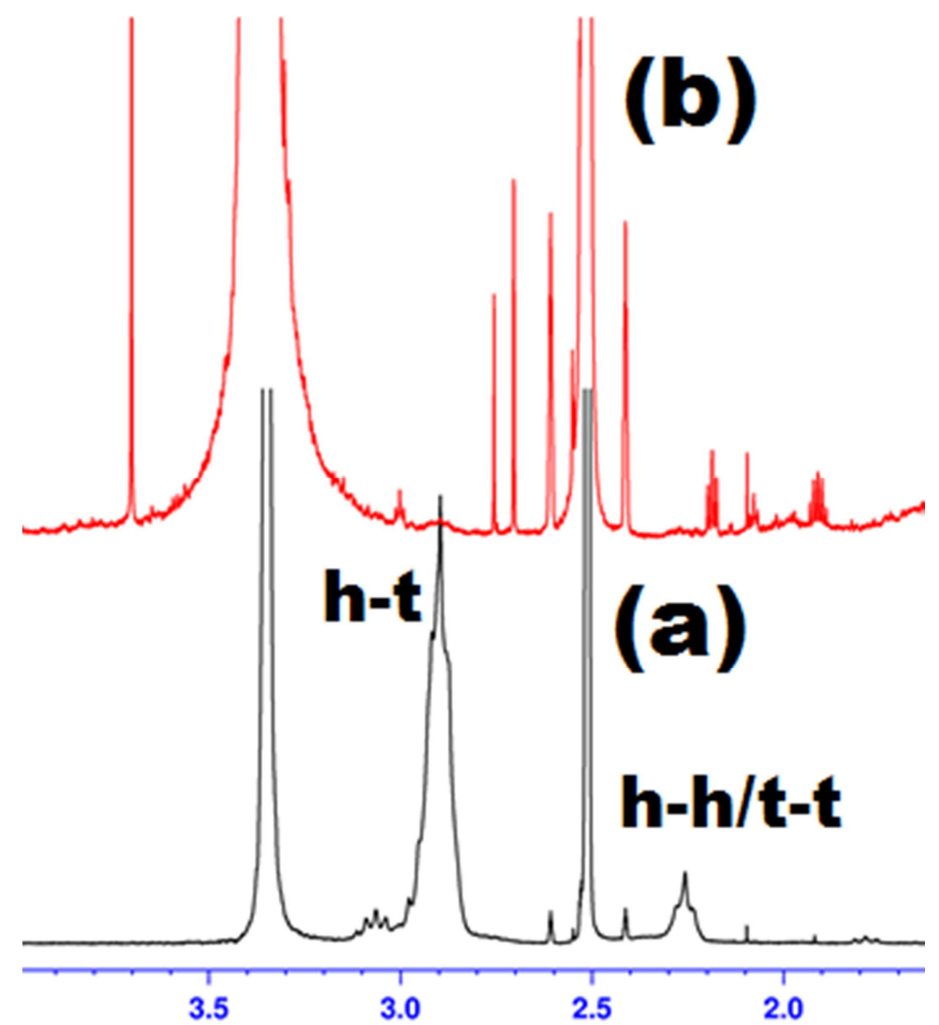




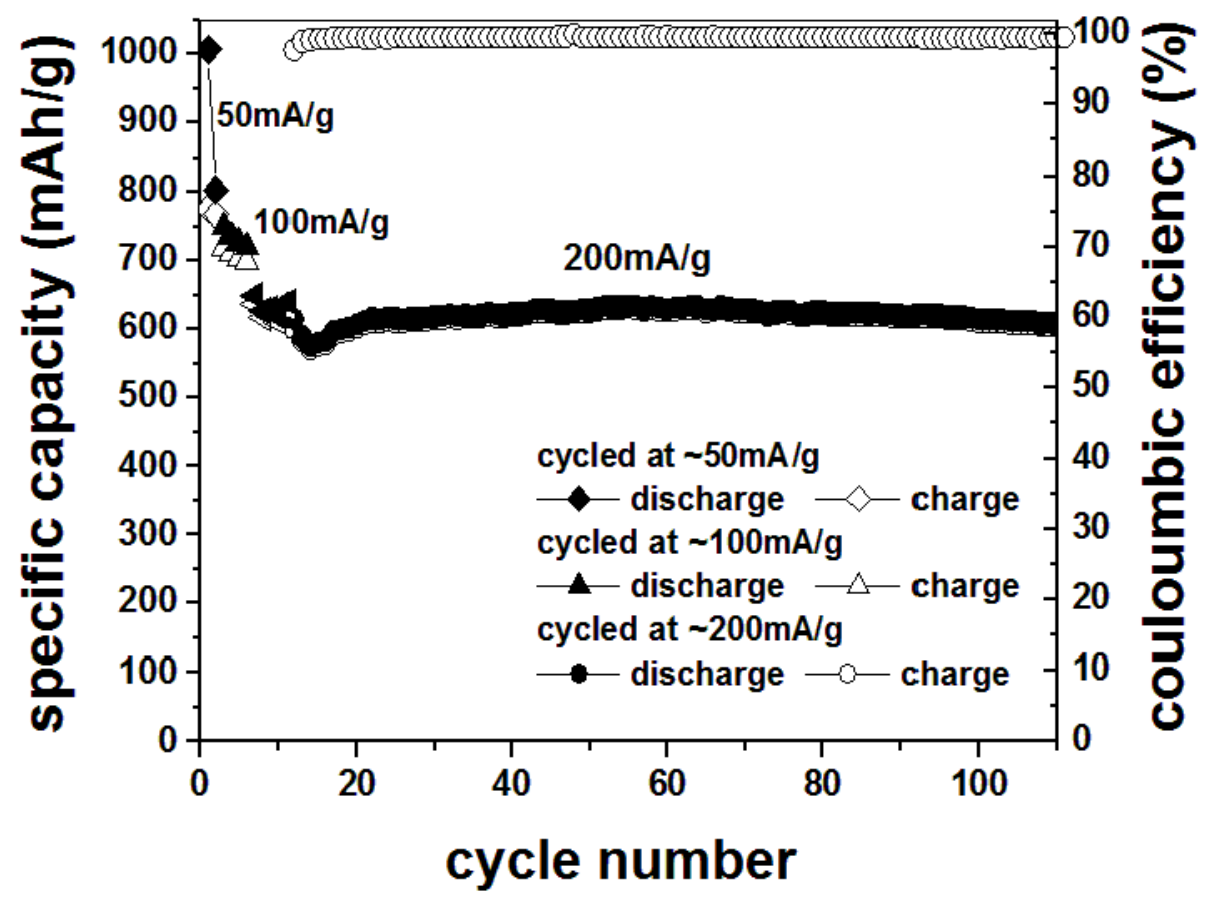




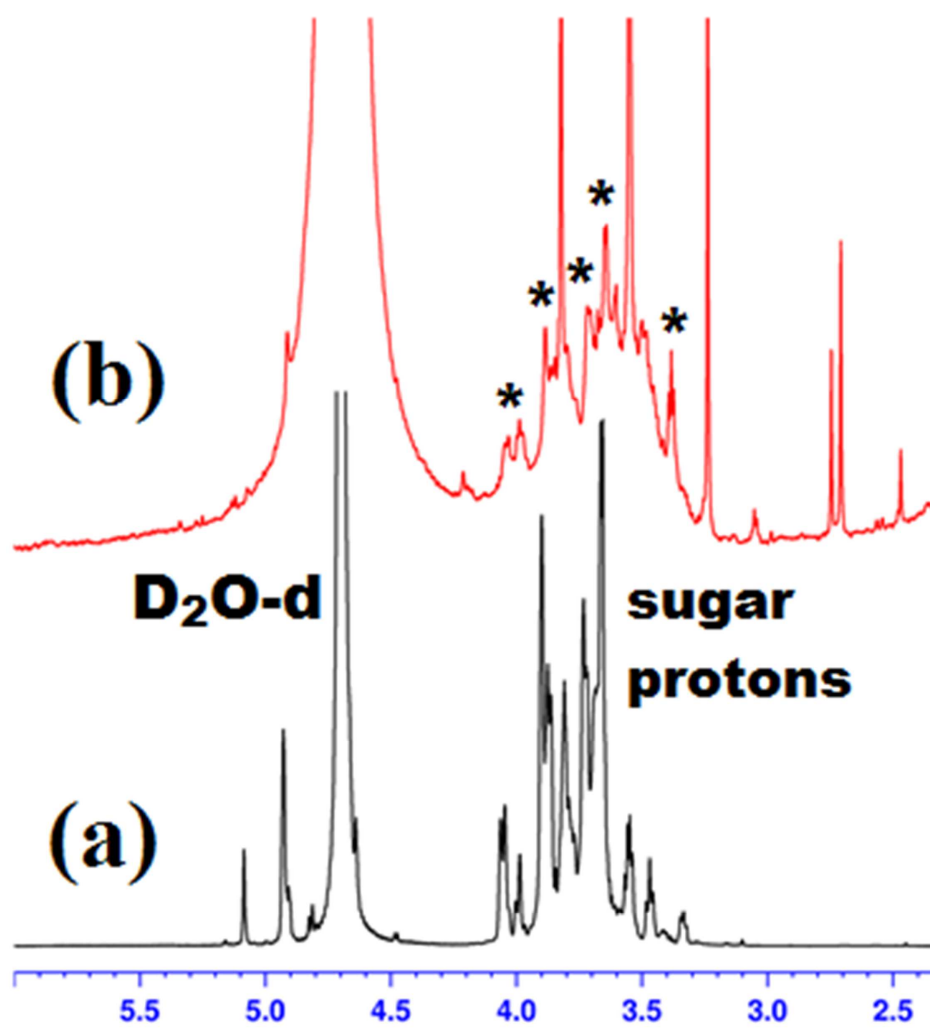




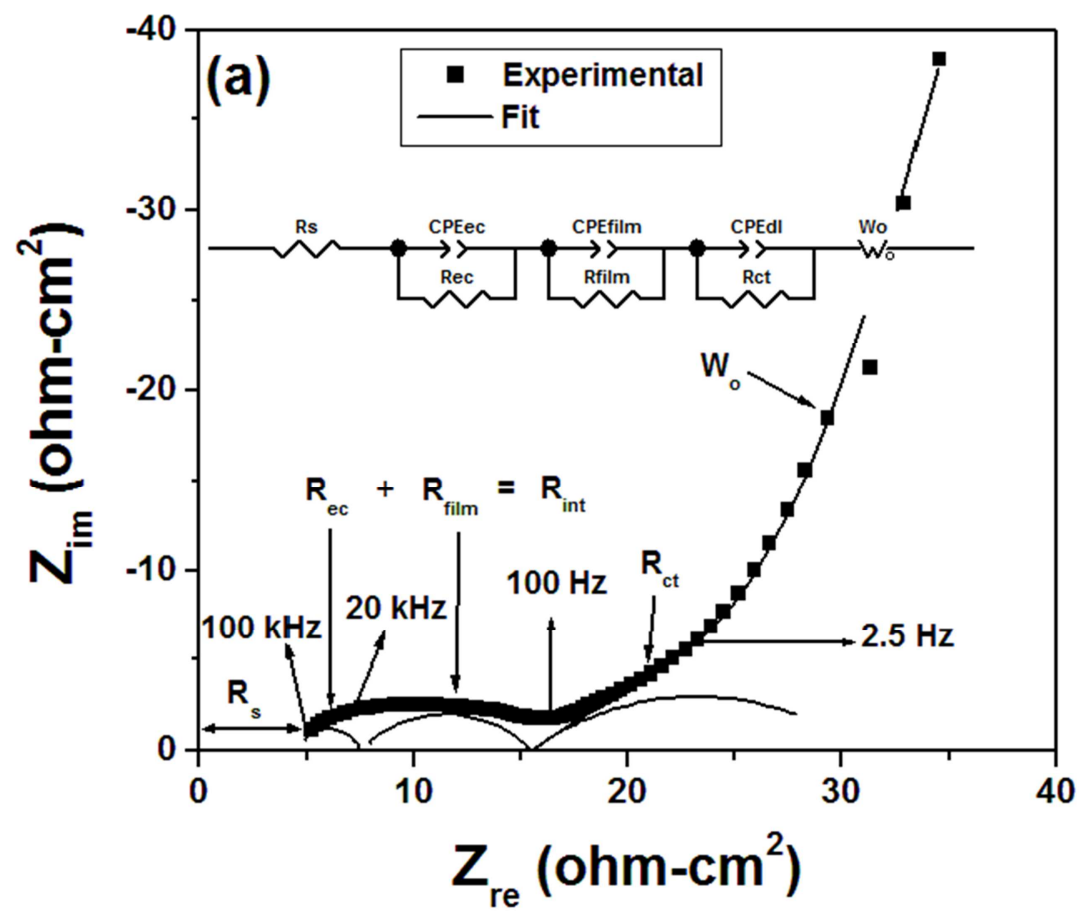




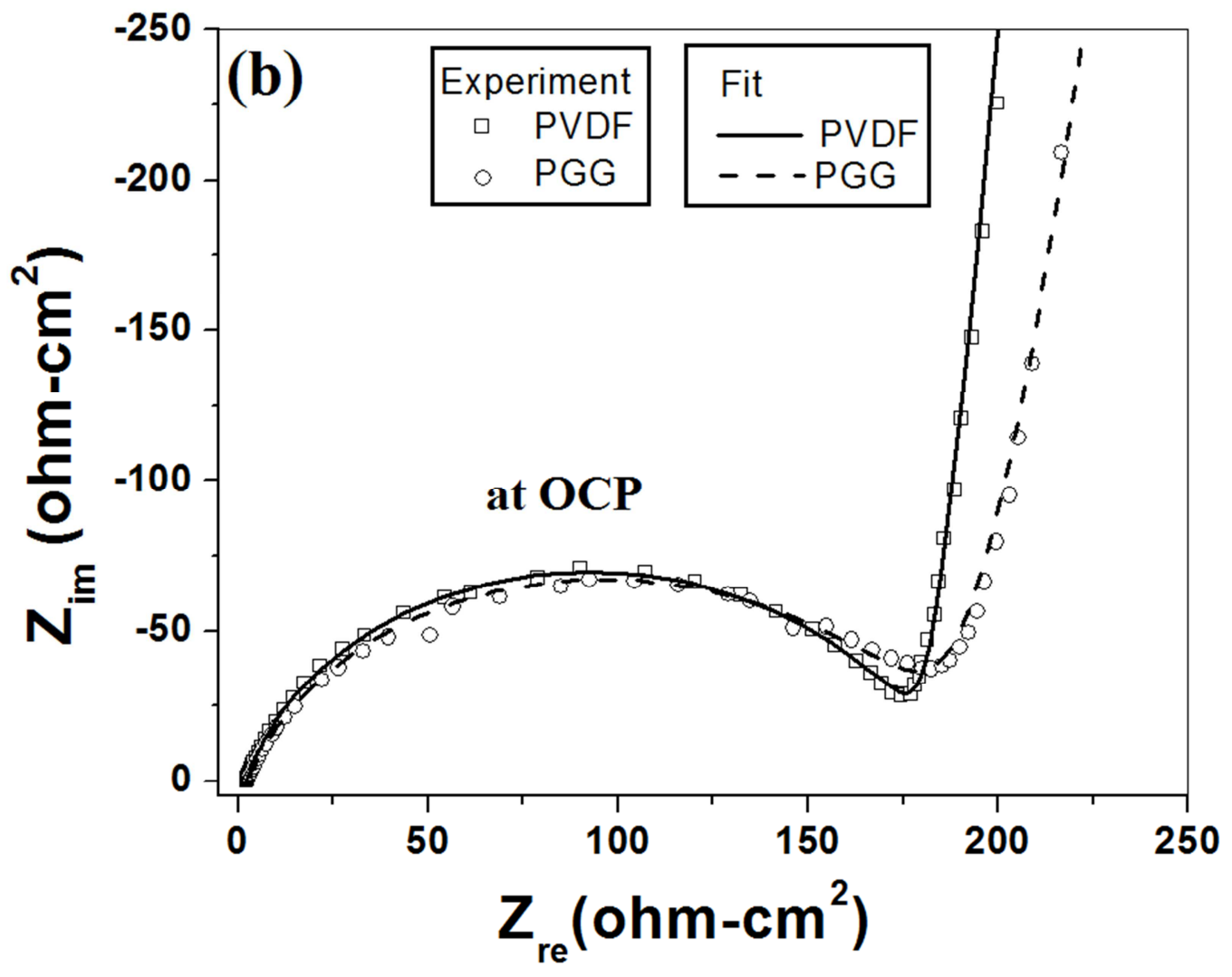




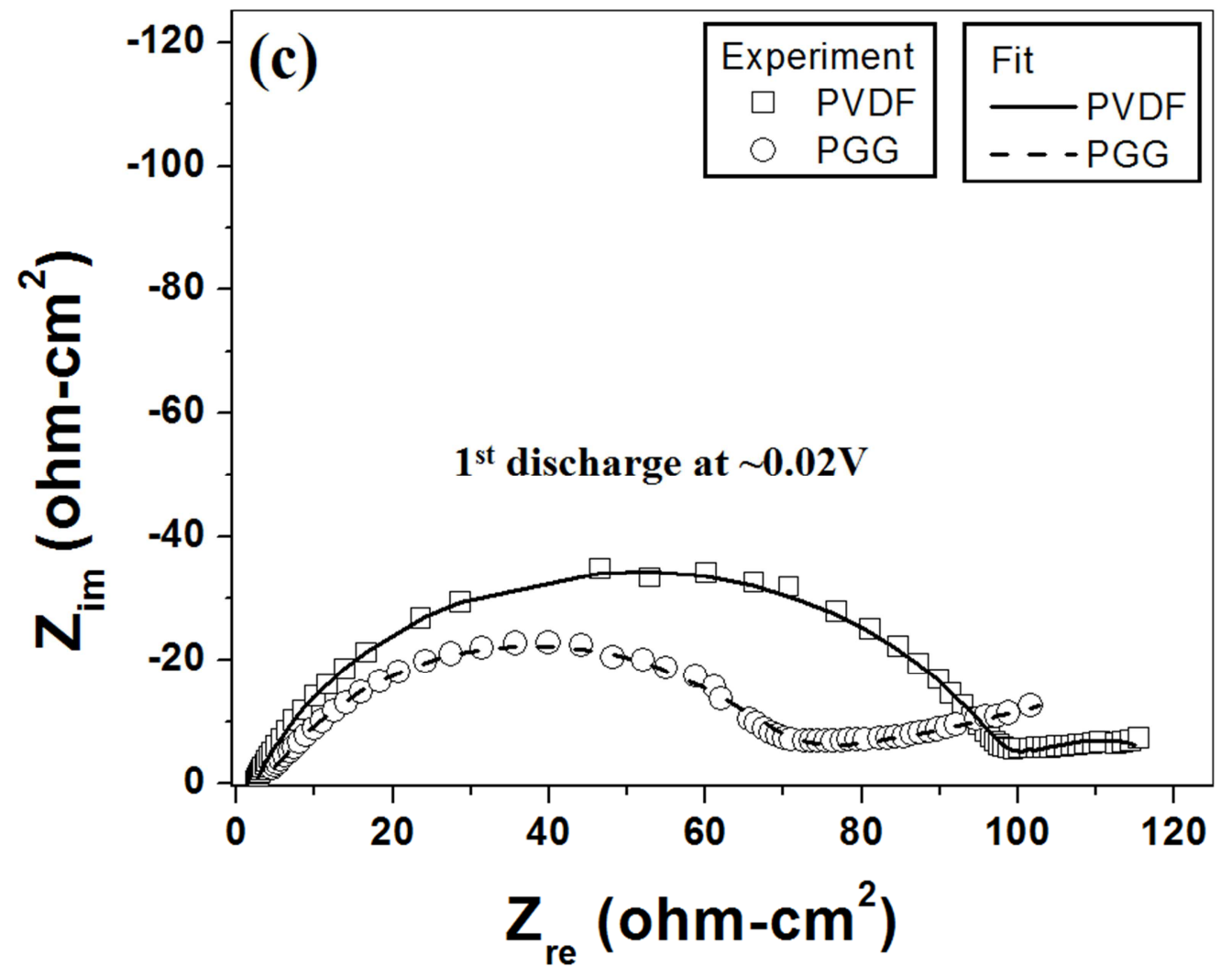




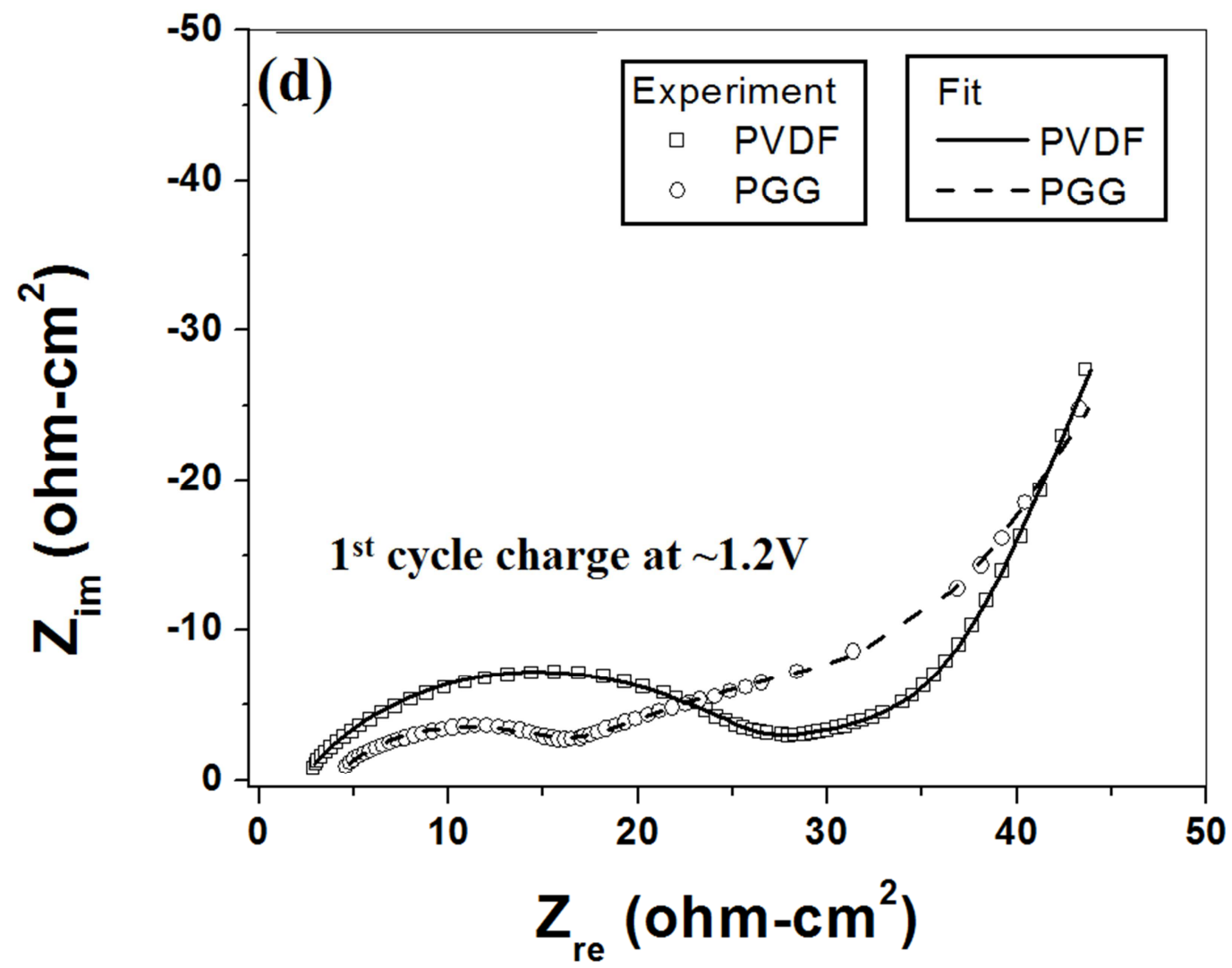




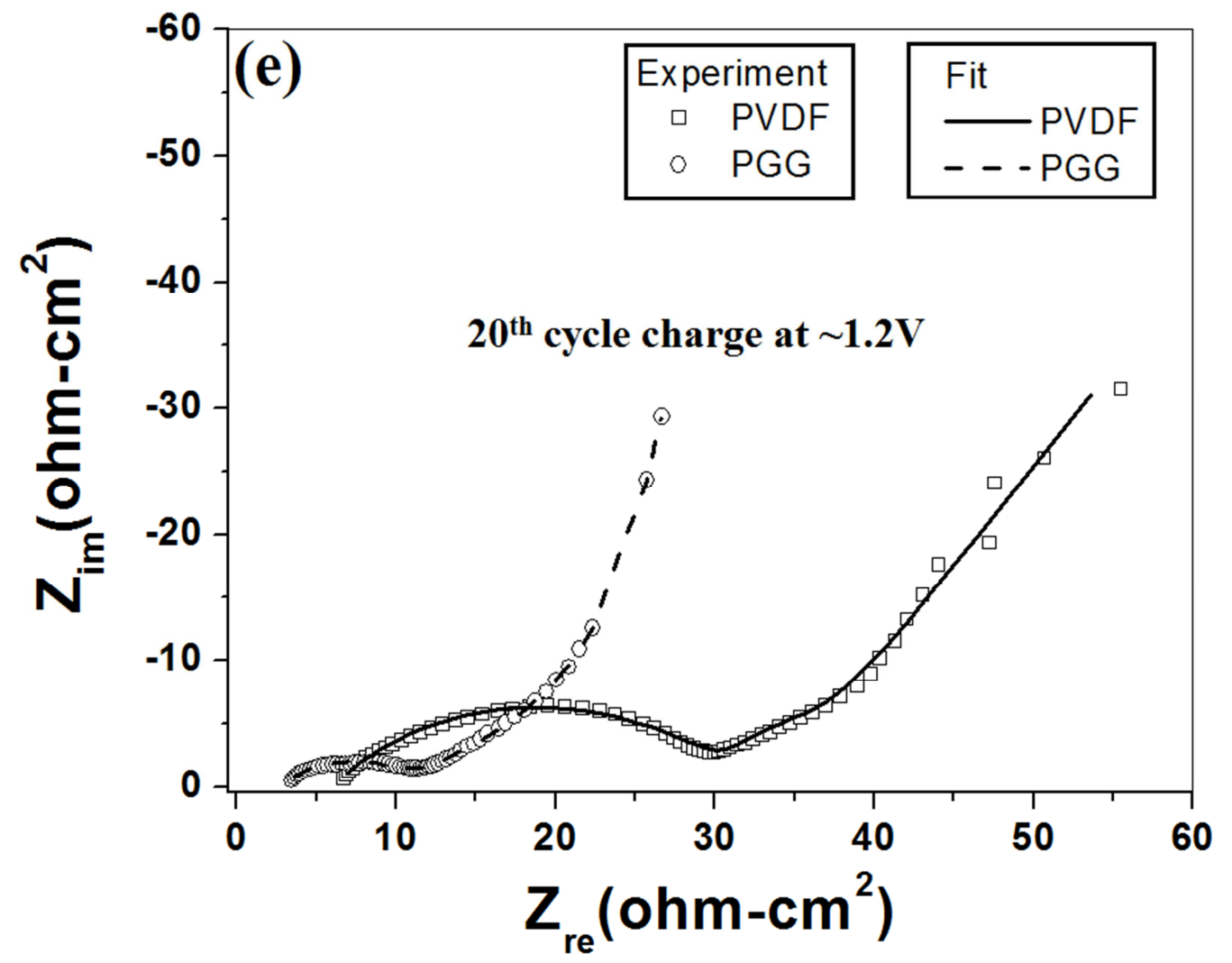




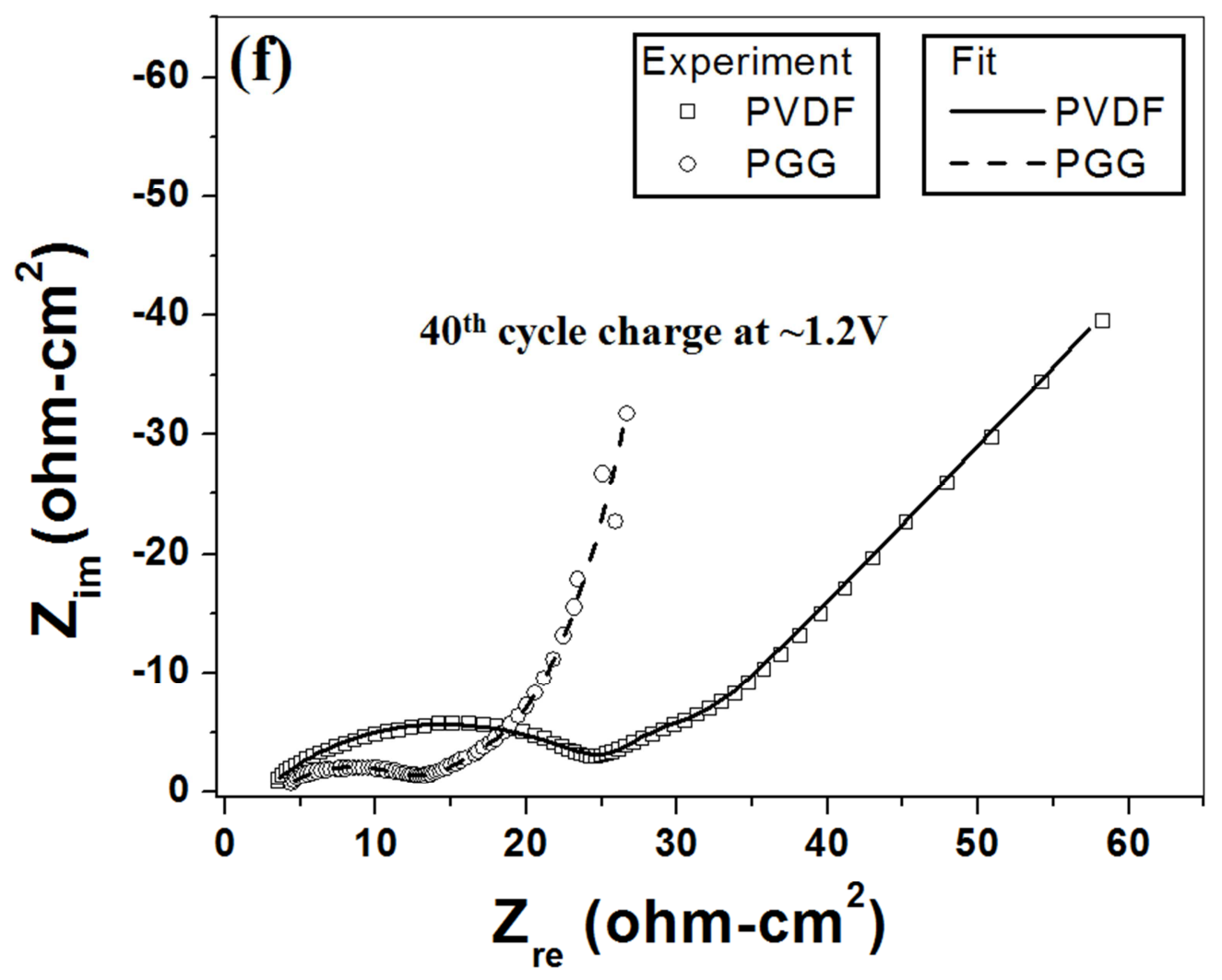

